\title{
THE ROLE OF VOUCHER SALE IN ADVANCE FOR A CAPITAL-CONSTRAINED SUPPLY CHAIN
}

\author{
Haijun WAnG ${ }^{1}$ AND GuAnmei LiU ${ }^{2, *}$
}

\begin{abstract}
This paper studies voucher sale as an operational method to raise working capital for a supply chain, which consists of a supplier and a capital-constrained retailer. The retailer takes advantage of an online platform to sell vouchers and to get access to borrowing from a bank. By formulating a Stackelberg game model, we show the retailer's possible order quantities in the cases without and with bank loan and analyze the impact of voucher sale on the retailer's optimal choice of order quantity and the supplier's optimal wholesale price. We find that a smaller voucher's price induces the retailer to be more likely to order with loan from a bank while a larger voucher's value induces an order quantity with the loan more difficult to be repaid. In addition, if voucher's price is large, the supplier decides a wholesale price which leads the retailer not to borrow from a bank; and if voucher's price is small, the supplier's optimal decision is obtained by anticipating the retailer to borrow from a bank. We also analyze the impact of voucher sale in the presence of trade credit financing on the firms' decisions. The results show that the voucher's price should be small so that the large; otherwise, the retailer either does not borrow from the supplier or may not repay the supplier. Besides, the supplier decides a wholesale price so that the retailer does not borrow or can repay the supplier, except that the voucher's value is large and the voucher's price is medium.
\end{abstract}

Mathematics Subject Classification. 90B06.

Received July 1, 2020. Accepted March 21, 2021.

\section{INTRODUCTION}

One of challenges faced by small- and medium-size firms (SMEs) is capital shortage during their operations. To diversify financial sources of SMEs and improve supply chain's financial efficiency, many financial methods are developed by tying welfare of key investors, customers and suppliers to SMEs so that SMEs have access to investors directly or to commercial bank indirectly [3,17]. Now external bank credit financing and internal trade credit financing are two widely used financial sources with $50 \%$ of SMEs financing through bank credit and $90 \%$ of SMEs financing through trade credit [16]. However, it still challenges some SMEs to finance due to the lack of tangible internal resources, high transaction costs and large operational risk [41].

As online platforms have made it more and more convenient for firms and consumers to interact, seeking operational method through online platforms to raise working capital from consumers is one solution to get

Keywords. Capital constraint, voucher sale, raise working capital, game theory.

1 Glorious Sun School of Business \& Management, Donghua University, Shanghai 200051, P.R. China.

2 School of Finance, Nanjing Audit University, Nanjing 211815, P.R. China.

*Corresponding author: lgmei@nau.edu.cn 
working capital for SMEs. In this movement, an innovative operational service provided by Alibaba Network Technology Co., Ltd, the largest online retail platform in Asia, stands out. For example, TMALL.com of Alibaba sells vouchers of a product online many days before "November 11" Singles' Festival [19]. Consumers who intend to buy a product during the Festival buy vouchers of the product in advance and as a result, SMEs on TMALL.com obtain working capital from consumers by this operational method of voucher sale. Similar vouchers are sold on some other online platforms such as Costco-Wholesale Online Shopping, Walmart.com and Amazon.com as well.

Voucher sale in advance allows SMEs to obtain working capital from consumers. Similar to advance selling, the voucher sale allows the retailer to obtain money before the product is delivered (e.g. $[7,9,28])$. Different from advance selling, a voucher just represents a part of money for a product and as a result, voucher sale in advance may not raise enough working capital for SMEs to order from upstream firms. In addition, given the fact that a voucher of "November 11" Singles' Festival entitles consumers holding it to buy products at a discount of double face value on the Festival. Consumers buy vouchers in advance to obtain a deep discount, however the deep discount decreases SMEs' profit from a product on the Festival. But the behavior of the consumers allows SMEs on TMALL.com to estimate market of a product [32,33]. Similar situation between supplier and retailer is considered by examining whether a supplier should offer advance-order discounts to encourage retailer to place a portion of its order in advance [8]. Therefore, voucher sale puts forward a corresponding solution by providing information about potential market demand before the demand is realized.

To address the problem of the role of voucher sale on supply chain operations, we examine a two-echelon supply chain consisting of a supplier and a capital-constrained retailer. By formulating a Stackelberg game model with the supplier as a leader and the retailer as a follower, the supplier first makes wholesale price decision and then the retailer makes order quantity decision. Before the decisions, the retailer sells vouchers in advance to obtain working capital. We analyze supply chain equilibriums in two cases depending on whether the retailer borrows money from a bank, and propose the impact of voucher sale on the retailer's choice of order quantity and the supplier's decision of wholesale price. We also analyze the impact of voucher sale in the presence of trade credit financing on the firms' decisions.

This study has three research questions. The retailer obtains working capital from voucher sale and has access to bank loan, and the first question is what are the retailer's order quantity and the supplier's wholesale price decisions considering the two sources of capital? The second question is whether obtaining working capital from just voucher sale or from both voucher sale and a bank is more profitable for the retailer? Analyzing a supply chain operation, we show the retailer's financial decision by combining it with operational decision, and compare the retailer's expected profits without and with loan. The third research question is whether it is possible for the supplier to make wholesale price decision by observing the retailer's behavior of voucher sale and how voucher sale affects the supplier's wholesale price decision? We analyze it by linking the supplier's decision to voucher's price and voucher's value. In this way, this study provides a roadmap for the retailer and the supplier to optimize their respective profits in the presence of voucher sale.

The contributions of this study mainly lie in the following aspects. First, for a capital-constrained supply chain, most of previous studies have focused on internal or external financing and their effects on supply chain, with no study examining finance through an operational way (e.g. voucher sale in advance). This study addresses this research gap by investigating voucher sale to raise working capital before the capital-constrained retailer's ordering. Second, regarding role of advance selling, few studies have considered it as a way to raise working capital. This study examines voucher sale in advance and the impact of a part of payment from consumers on operational decisions. Third, this study also takes voucher sale as a way to estimate market demand. While most studies view voucher sale as a promotion method to increase market demand and firms' profit.

The remainder of this study is organized as follows. Section 2 reviews the literature. Section 3 introduces model description and framework. Section 4 sets up a Stackelberg game model to analyze the firms' decisions with voucher sale. Section 5 provides an extension of the voucher sale in the presence of trade credit financing. Section 6 concludes the study and proposes future extensions to our research. 


\section{Literature REVIEW}

Our research draws on three separate streams of literature: operations and finance interactions, advance selling and online promotion. In this section, we provide a review of prominent research in each stream and position our research at the point of their intersection.

Recently, operations and finance interactions have received attention in the academic literature. The existing literature has put forward external financing and internal financing to solve problem of capital constraint in a supply chain $[25,30,42]$. Yang et al. [43] implement a financing method between suppliers and financing institutions to analyze the role and efficiency of buyer intermediation in financing. Chod [10] shows that, when products differ in cost, revenue, or demand parameters, debt financing distorts retailer's inventory decision. Deng et al. [13] consider a supply chain with one assembler and multiple capital-constrained suppliers, and they compare buyer finance with bank finance in the supply chain. Devalkar and Krishnan [14] analyze, in the present of supplier moral hazard and costly working capital financing, how trade credit coordinates a two-echelon supply chain. Wu et al. [37] study financing of bank credit and trade credit, and effects of them respectively on inventory decisions. Wu et al. [38] consider two asymmetric retailers and a manufacturer in the presence of retailers' inventory competition, trade credit financing and demand uncertainty. Lu [26] investigates a case that a multinational firm invests in a capital-constrained retailer and gets optimal financing strategy between bank credit financing and trade credit financing. Zhan [45] considers a new bank financing model in which the supplier promises to provide a partial warranty for the bank credit risk if the retailer goes bankrupt.

It is worth noting that Gao et al. [16] study an SCF (i.e. supply chain finance) system that either retailer or manufacturer faces a capital constraint and must borrow capital through an online P2P lending platform. Our paper is significantly different from Gao et al. [16] in three aspects. First, Gao et al. [16] analyze that firms' capital is from online P2P lending platform which serves as an external financing channel with an objective of maximizing expected profit while we assume loan is risk-free to focus on role of capital raising from consumers. Therefore, we are able to investigate effect of a part of consumers' payment on firms' operation decisions. Second, Gao et al. [16] explore interaction of a P2P lending platform, a manufacturer and a retailer, while we only consider interaction between a supplier and a retailer with a bank determining lending rate passively and consumers' related parameters being exogenous. Thus, we identify the supplier's and the retailer's decision by considering an operational method of getting money online from consumers. Third, we incorporate a stage which is before the retailer's ordering and in the stage, the retailer raises working capital through an online platform accompanied by getting some information about market demand. Gao et al. [16] do not address this condition.

Many papers about advance selling address the condition that the retailer gets some information about market demand and firms benefit from advance selling. Yu et al. [44] show that whether firms benefit from advance selling depends on market parameters such as consumer valuation and capacity level. They find that interdependence of consumer valuation determines different policies of advance selling. Khouja and Zhou [23] systematically examine selling products and advance selling of gift cards in a supply chain. Two channels of buying gift cards are considered with service provider and retailer providing same kind of gift cards. Noparumpa et al. [31] investigate a form of flexibility with advance selling of wine to mitigate wine quality rating risk. Wu et al. [39] analyze effect of placing advance orders at a discount and taking a new product to market as research object. They focus on how advance selling increase total expected sales by exploiting customers' valuation and estimate total sales to reduce cost of safety stock. Cachon and Feldman [2] prove that advance selling may not increase profits of a monopolist when competition exists. Jin et al. [20] consider advance selling to be a financing strategy and compare it with delay payment in a capital-constrained supply chain under uncertain demand. They show that retailer prefers advance selling on condition of low capital and confronting pricesensitive customers. Wei and Zhang [36] study an advance selling strategy by considering strategic consumer behavior with results showing that seller's production decision is contingent on an advance selling target. Xiao et al. [40] formulate two dynamic pricing schemes to examine equilibrium of a seller's pricing strategies.

This line of research studies how to use advance selling as an operational method to increase demand, while it does not capture how a part of revenue from consumers before the retailer's ordering affects the retailer's order 
quantity decision and the supplier's wholesale price decision. We consider a part of payment from consumers as the retailer's source of working capital. In addition, the retailer considers whether to borrow from a bank if it is necessary. With Stackelberg game models, we reveal the retailer's order quantity of two cases by considering a part of payment from consumers, and the impact of the part of payment on firms' optimal decisions.

Our paper is also related to literature about online promotion for that online promotion offers a way of predicting market demand, influencing market demand and optimizing profit. Jiang et al. [18] suggest that firms should jointly consider online price promotion and product recommendations when they make optimal decisions. They provide attractive price discounts to motivate consumers to purchases and use online recommendation systems to deal with non-discounted items. Chong et al. [12] investigate a way of predicting consumer product demands by combining online promotional marketing with online reviews. Jiang et al. [19] demonstrate under what conditions dual channel retailers promote online by formulating a long-term optimization model. Kim and Krishnan [24] study online consumer-retailer relationship and model effect of price promotion on the relationship as a function. Zhang et al. [46] examine a supply chain consisting of an online retailer and a capacitated carrier. In their model, online retailer influence demand by setting price promotion while cost of carrier's capacity can be very high. Different from this line of research, we assume that consumers buying vouchers in advance obtains a discount of products, while there are consumers buying products without vouchers.

\section{MODEL DESCRIPTION AND FRAMEWORK}

We consider a two-echelon supply chain consisting of a supplier (hereinafter referred to as she) and a retailer (hereinafter referred to as he). The supplier is a firm with sufficient working capital, and the retailer is a SME who faces financial constraint. Before a holiday, the retailer sells vouchers in advance through an online platform to raise working capital from consumers and may borrow from a bank. After that, the supplier offers a wholesale price contract to the retailer and given the contract, the retailer determines the order quantity to satisfy consumers in an upcoming holiday. Table 1 defines the parameters and variables used throughout the paper.

TABLE 1. Parameter and variable definitions.

\begin{tabular}{ll}
\hline \hline Notation & Description \\
\hline$p$ & Retail price of the product \\
$c$ & Unit production cost \\
$T$ & Voucher's price \\
$\beta$ & Voucher's value \\
$D$ & Demand for voucher \\
$\alpha$ & Changing ratio of consumers buying product which is a \\
& random variable \\
$u$ & Lower bound of changing ratio \\
$v$ & Upper bound of changing ratio \\
$B$ & Bank loan \\
$f(\alpha)$ & Probability density function of changing ratio \\
$F(\alpha)$ & Cumulative distribution function of changing ratio \\
$R_{f}$ & Risk-free interest rate \\
$R_{b}$ & Bank lending rate \\
$\pi_{r}$ & Retailer's expected profit \\
$\pi_{s}$ & Supplier's expected profit \\
Decision variables & \\
$w$ & Supplier's wholesale price \\
$q$ & Retailer's order quantity \\
\hline
\end{tabular}


The retailer sells vouchers to consumers through an online platform at unit price $T$ before a holiday and sells products at retail price $p$ in holiday. We assume expenditures of selling vouchers and products through an online platform are zero. A voucher allows a consumer holding it to save $\beta T$ off to buy a product in holiday. The voucher's value $\beta$ satisfies $\beta>1$ and $\beta T<p$ because the consumers would be willing to buy the voucher if they save more money by buying the voucher $($ i.e. $\beta T>T$ ) and the retailer would sell the voucher if he obtains positive revenue from the product (i.e. $p-\beta T>0)$. Then, the consumers with vouchers buy the product at unit price $p-\beta T$ while the consumers without vouchers buy the product at unit price $p$.

We denote market demand for vouchers by $D$ and assume that the consumers buying vouchers will buy products during the holiday. Therefore, $D$ is also the demand for products of consumers with vouchers and it is realized before the retailer's ordering. The total demand of products in holiday is assumed to be $\alpha D$, where $\alpha$ is a coefficient of $D$ and it is a random variable to characterize the uncertainty of demand. It is obvious that $\alpha>1$ under the assumption that the consumers buying vouchers will buy products. We assume that $\alpha>1$ has a cumulative distribution function (CDF) $F(\alpha)$ on $[u, v]$, where $u \geq 1$ and $v>u$. $F(\alpha)$ is monotonically increasing with $\alpha$ and its probability density function (PDF) $f(\alpha)>0$. Inverse distribution of $F(\alpha)$ is $F^{-1}(\alpha)$. The assumptions of the random variable are commonly adopted in supply chain models (e.g. $[6,11,15,27])$. With $D$ being demand for products of consumers with vouchers, $(\alpha-1) D$ is demand for products of consumers without vouchers.

As demand for vouchers is $D$ and voucher's price is $T$, the retailer's working capital from voucher sale is $T D$. Without loss of generality, we assume the retailer's initial capital is zero, which is similar to work of Jing et al. [21] and Cao et al. [4]. This assumption indicates that the retailer's working capital is raised from voucher sale. In addition to the voucher sale, the retailer may borrow from a bank directly through his own channel or indirectly through an online platform. To focus on the impact of voucher sale, we only consider bank loan (i.e. $\left.B=(w q-T D)^{+}\right)$and its interest $\left(i . e . R_{b}\right)$ by assuming expenditure of borrowing from a bank through an online platform to be zero. The bank is in a competitive market and has access to unlimited funds at a risk-free interest rate, $R_{f}$ (e.g. [6]).

The supplier has enough capital to produce products at unit cost $c$ for the retailer's ordering. The retailer is capital-constrained and his liability is limited which is similar to the assumption of work of Buzacott and Zhang [1] and Ni et al. [30]. That means, if the retailer's revenue exceeds his bank loan, he repays the loan at the end of the holiday. Otherwise, the retailer repays the loan with his all revenue and does not need to repay the remainder. This assumption is reasonable, because the retailer is capital-constrained and if his revenue does not cover bank loan, there is no other channel for him to obtain money to repay the loan. In addition, we assume that the loan is employed by the retailer to make orders instead of other business.

The sequence of events is as follows. Before a holiday, the capital-constrained retailer sells vouchers at unit price $T$ through an online platform. Many consumers are attracted to buy vouchers and demand for vouchers, $D$, is realized. The working capital that the retailer raises from consumers is $T D$ and the retailer realizes that his revenue from consumers with vouchers will be $(p-\beta T) D$ after the demand for products is realized. Then the supplier sets a wholesale price which is denoted by $w$. Observing the wholesale price, the retailer makes the decision of order quantity which is denoted by $q$. Meanwhile, the retailer may borrow $B=(w q-T D)^{+}$from a bank with a lending rate $R_{b}$, which is simultaneously announced by competitive banks. In holiday, consumers with and without vouchers buy products from the retailer and the demand for products is realized. After holiday, the retailer repays bank loan if his revenue covers the loan; otherwise, he repays bank loan with his all revenue. We use Figure 1 to illustrate the sequence of the events above.

\section{The FIRMS' DECISIONS With VOUCHER SALE IN THE PRESENCE OF BANK FINANCING}

In this section, we analyze the firms' decisions with voucher sale. By proceeding backwards, we first derive the retailer's possible order quantities and get the order decision for a given wholesale price, and then obtain the supplier's optimal wholesale price to obtain the equilibriums of the Stackelberg game. 


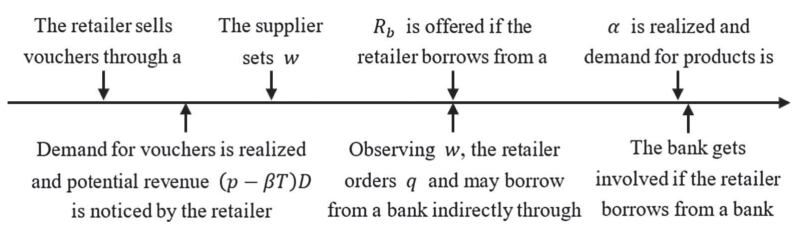

FiguRE 1. Sequence of events.

\subsection{The retailer's decision of order quantity}

Depending on whether borrowing from a bank, we obtain the retailer's optimal order quantities without and with loan from a bank and then analyze the impact of voucher's price and voucher's value on the retailer's order decisions.

\subsubsection{The case without loan from a bank}

In this case, the retailer does not borrow from a bank and he orders with working capital from voucher sale. The retailer's working capital from voucher sale is $T D$ and he pays $w q$ to the supplier before holiday. As demand for vouchers $D$ also represents demand of consumers with vouchers, the retailer's revenue from consumers with vouchers is $(p-\beta T) D$. With $(\alpha-1) D$ being demand of consumers without vouchers, the retailer's expected revenue from consumers without vouchers is $p \min [q-D,(\alpha-1) D]$. In addition, it is necessary to notice that the retailer's payment on ordering does not exceed his working capital and the retailer needs to order at least $D$ to satisfy demand of consumers with vouchers.

According to the above, given the supplier's wholesale price, the retailer's optimization problem of the case without loan from a bank is

$$
\begin{gathered}
\pi_{r}^{N L}=(p-\beta T) D+p E \min [q-D,(\alpha-1) D]-w q+T D \\
\text { Subject to: }\left\{\begin{array}{c}
w q \leq T D \\
q \geq D
\end{array}\right.
\end{gathered}
$$

To optimize the expected profit, the retailer's order quantity is constrained by his working capital and demand of consumers with vouchers. The following lemma characterizes the retailer's optimal order quantity in the case without loan from a bank.

Lemma 4.1. For the case without loan from a bank, the retailer's optimal order quantity is $q^{N L^{*}}$ : (i) if $T<w F^{-1}\left(1-\frac{w}{p}\right), \quad q^{N L^{*}}=\frac{T D}{w}$ with $w \leq T$; and (ii) if $T \geq w F^{-1}\left(1-\frac{w}{p}\right), q^{N L^{*}}=q^{N L}$ where $q^{N L}=D F^{-1}\left(1-\frac{w}{p}\right)$.

As it is shown in Lemma 4.1, the order quantity to obtain the retailer's maximal expected profit is $q^{N L}$, however, the retailer does not always order $q^{N L}$ for the first constraint in (4.1). Whether the retailer can order $q^{N L}$ is determined by the retailer's working capital from voucher sale (i.e. $T D$ ), which is determined by $T$ for $D$ is assumed to be constant. As a result, the retailer's order quantity reacts to voucher's price. Specifically, when voucher's price is smaller than $w F^{-1}\left(1-\frac{w}{p}\right)$, the retailer pays all working capital to order and the wholesale price should be lower than $T$ so that the retailer can order at least $D$ to satisfy consumers with vouchers; otherwise, the retailer orders $q^{N L}$ to obtain maximal expected profit.

\subsubsection{The case with loan from a bank}

In this case, the retailer orders with capital from voucher sale and loan from a bank. Notice that the retailer's working capital from voucher sale is $T D$ and his payment to the supplier is $w q$. Then before holiday, the bank lends $B=(w q-T D)^{+}$. After the holiday, the retailer obtains $(p-\beta T) D$ from consumers with vouchers and 
$p \min [q-D,(\alpha-1) D]$ from consumers without vouchers. The bank either obtains the loan and its interest (i.e. $\left.B\left(1+R_{b}\right)\right)$ or the retailer's total revenue (i.e. $\left.(p-\beta T) D+p \min [q-D,(\alpha-1) D]\right)$. Then the bank's zero expected profit condition is thus

$$
B\left(1+R_{f}\right)=E \min \left\{B\left(1+R_{b}\right),(p-\beta T) D+p \min [q-D,(\alpha-1) D]\right\} .
$$

Since the retailer can predict his revenue from consumers with vouchers (i.e. $(p-\beta T) D)$, the retailer could make decision on the conditions that he can repay or may repay bank loan. The condition that the retailer can repay the bank loan is $(p-\beta T) D \geq B\left(1+R_{b}\right)$ and then equation (4.2) is reduced to $B\left(1+R_{f}\right)=B\left(1+R_{b}\right)$ which means $R_{f}=R_{b}$. Therefore, the condition that the retailer can repay the bank loan is $(p-T) D \geq B\left(1+R_{f}\right)$. Contrary to this condition, the condition that the retailer may repay bank loan is $(p-\beta T) D<B\left(1+R_{f}\right)$.

In the condition that the retailer can repay bank loan, the retailer pays $w q=T D+B$ to the supplier before holiday. In the holiday, the retailer's total revenue is $(p-\beta T) D+p \min [q-D,(\alpha-1) D]$, and the retailer can repay $B\left(1+R_{b}\right)$ after the holiday in this condition. Besides, there are three constraints: payment on ordering is larger than working capital from voucher sale, revenue from consumers with vouchers can repay bank loan and the order quantity at least satisfies consumers with vouchers. Then the retailer's optimization problem is

$$
\begin{aligned}
\pi_{r}^{L R}=(p-\beta T) D+p E \min [q-D, & (\alpha-1) D]-B\left(1+R_{b}\right) \\
w q & >T D \\
\text { Subject to: } & \left\{\begin{array}{c}
(p-\beta T) D \\
\geq B\left(1+R_{f}\right) . \\
q \geq D
\end{array}\right.
\end{aligned}
$$

In the condition that the retailer may repay bank loan, the retailer obtains zero expected profit if the bank loan is not repaid, which is different from the objective function of (4.3). In addition, the retailer makes his order quantity decision on the constraints that his payment on ordering is larger than working capital from demand for vouchers, his revenue from consumers with vouchers may repay bank loan and his order quantity is at least $D$ to satisfy consumers with vouchers. Thus, the retailer's optimization problem is

$$
\begin{aligned}
\pi_{r}^{L M}=\{(p-\beta T) D+p E \min [q-D & \left.,(\alpha-1) D]-B\left(1+R_{b}\right)\right\}^{+} \\
w q & >T D \\
\text { Subject to: } & \left\{\begin{aligned}
(p-\beta T) D & <B\left(1+R_{f}\right) . \\
q & \geq D
\end{aligned}\right.
\end{aligned}
$$

Along with the above analysis, we obtain Lemma 4.2 to summarize the retailer's optimal order quantity $q^{L R^{*}}$ with the loan can be repaid and $q^{L M^{*}}$ with the loan may be repaid for a given wholesale price in the case of borrowing from a bank.

Lemma 4.2. By borrowing from a bank, (i) if $T \geq w F^{-1}\left[1-\frac{w\left(1+R_{f}\right)}{p}\right], q^{L R^{*}}=q^{L M^{*}}=\frac{T D}{w}$ with $w \leq T$; (ii) if $T<w F^{-1}\left[1-\frac{w\left(1+R_{f}\right)}{p}\right], \quad q^{L R^{*}}=q^{L R}$ if $\frac{p-\beta T}{1+R_{f}}+T \geq w F^{-1}\left[1-\frac{w\left(1+R_{f}\right)}{p}\right]$ and $q^{L R^{*}}=\frac{B_{L}}{w}+\frac{T D}{w}$ with $w \leq$ $\frac{p-\beta T}{1+R_{f}}+T$ otherwise; and (iii) if $T<w F^{-1}\left[1-\frac{w\left(1+R_{f}\right)}{p}\right], \quad q^{L M^{*}}=q^{L M}$ if $\frac{p-\beta T}{1+R_{f}}+T<w F^{-1}\left[1-\frac{w\left(1+R_{f}\right)}{p}\right]$ and $q^{L M^{*}}=\frac{B_{L}}{w}+\frac{T D}{w}$ with $w \leq \frac{p-\beta T}{1+R_{f}}+T$ otherwise.

Where $q^{L R}=q^{L M}=D F^{-1}\left[1-\frac{w\left(1+R_{f}\right)}{p}\right]$.

In Lemma 4.2, the retailer's optimal order quantity is divided by borrowing from a bank. We denote $B_{L}=$ $\frac{(p-\beta T) D}{1+R_{f}}$ as discounted value of revenue from consumers with vouchers. No matter whether the loan can be repaid or may be repaid, the retailer orders $\frac{T D}{w}$ if $T \geq w F^{-1}\left[1-\frac{w\left(1+R_{f}\right)}{p}\right]$ because the voucher's price is large enough so that the retailer does not need to borrow from a bank. If $T<w F^{-1}\left[1-\frac{w\left(1+R_{f}\right)}{p}\right]$, the retailer borrows from 
a bank and he obtains an order quantity $q^{L R}$ with the loan can be repaid if $\frac{p-\beta T}{1+R_{f}}+T \geq w F^{-1}\left[1-\frac{w\left(1+R_{f}\right)}{p}\right]$ is also satisfied. Otherwise, the retailer orders with a loan exactly equaling to $B_{L}$ (i.e. $w q^{L R^{*}}-T D=B_{L}$ ) which is the result of the constraint that the loan can be repaid. Contrary to the condition that the loan can be repaid, if $\frac{p-\beta T}{1+R_{f}}+T<w F^{-1}\left[1-\frac{w\left(1+R_{f}\right)}{p}\right]$, the retailer obtains an order quantity $q^{L M}$ with the loan may be repaid and he orders with a loan exactly equaling to $B_{L}$ otherwise. In addition, if the optimal order quantity can not be obtained, the wholesale price should satisfy $w \leq T$ or $w \leq \frac{p-\beta T}{1+R_{f}}+T$ so that the retailer can order at least $D$ to satisfy consumers with vouchers.

\subsubsection{The retailer's choice of order quantity}

So far, we obtain the retailer's optimal order quantities in the case without and with loan from a bank by selling vouchers. Now we analyze the retailer's choices of order quantity by comparing the retailer's expected profits.

We define three thresholds of voucher's price $T$. The first threshold, denoted as $T^{N L}$, satisfies that the retailer exactly obtains the optimal order quantity without loan from a bank by working capital from demand for vouchers (i.e. $T^{N L} D=w q^{N L}$ ). Similarly, the second threshold, denoted as $T^{L R}$, is a voucher's price that the retailer exactly obtains the optimal order quantity with bank loan can be repaid by working capital from demand for vouchers (i.e. $T^{L R} D=w q^{L R}$ ). Denoted as $T^{L M}$, the third threshold satisfies $w q^{L M}-T^{L M} D=B_{L}$ and it demonstrates that the retailer exactly obtains the optimal order quantity with loan may be repaid by borrowing $B_{L}$, where $B_{L}$ is the same as that in Lemma 4.2. There is a threshold of voucher's value $\beta$ which is defined as $\hat{\beta}=\frac{p}{T^{L R}}$ and it is a ratio of retail price and voucher's price that bank loan can be repaid.

In Proposition 4.3, we show the impact of voucher's price with a large voucher's value on the retailer's expected profits.

Proposition 4.3. For $\beta>\hat{\beta}$, the retailer's expected profits (i) $\pi_{r}^{L R^{*}}>\pi_{r}^{N L^{*}}$ and $\pi_{r}^{L R^{*}}>\pi_{r}^{L M^{*}}$ if $T<T^{L M}$, (ii) $\pi_{r}^{L M^{*}}>\pi_{r}^{N L^{*}}$ and $\pi_{r}^{L M^{*}}>\pi_{r}^{L R^{*}}$ if $T^{L M} \leq T<T^{L R}$, (iii) $\pi_{r}^{L M^{*}}=\pi_{r}^{N L^{*}}=\pi_{r}^{N L^{*}}$ if $T^{L R} \leq T<T^{N L}$, and (iv) $\pi_{r}^{N L^{*}}>\pi_{r}^{L R^{*}}=\pi_{r}^{L M^{*}}$ if $T \geq T^{N L}$.

Proposition 4.3 compares the retailer's expected profits with a large $\beta$. The retailer's expected profits are compared for a given wholesale price because the retailer's decision is made after he observes the supplier's wholesale price. As illustrated in Figure 2, if $T<T^{L M}$, when the retailer orders with no loan, the maximal expected profit is $\pi_{r}^{N L^{*}}$. However, the retailer's expected profit is larger when the retailer increases his order quantity by borrowing from a bank. And the retailer's maximal expected profit can increase to $\pi_{r}^{L R^{*}}$. After the retailer's expected profit reaches $\pi_{r}^{L} R^{*}$, the profit decreases when the retailer still increases his order quantity. If $T^{L M} \leq T<T^{L R}$, by not borrowing from a bank, the retailer's maximal expected profit is $\pi_{r}^{N L^{*}}$. By borrowing from a bank to increase the order quantity, the retailer's expected profit can increase to $\pi_{r}^{L R^{*}}$ with the loan can be repaid. For $T \geq T^{L M}$, it is not easy for the retailer to repay the loan because the retailer's revenue from consumers with vouchers (i.e. $(p-\beta T) D)$ is not large enough. If he takes some risks that the bank loan may not be repaid, the retailer can obtain the maximal expected profit $\pi_{r}^{L M^{*}}$. If $T^{L R} \leq T<T^{N L}$, the retailer's order quantities without and with loan are all bounded by the constraint of working capital from voucher sale. Therefore, no matter whether the retailer intends to borrow from a bank or not, the retailer's expected profits are equal by ordering with working capital from voucher sale. If $T \geq T^{N L}$, the retailer obtains enough working capital from voucher sale to earn the maximal expected profit without borrowing from a bank (i.e. $\pi_{r}^{N L^{*}}$ ).

In Proposition 4.4, we show the impact of voucher's price with a small voucher's value on the retailer's expected profits.

Proposition 4.4. For $\beta \leq \hat{\beta}$, the retailer's expected profits (i) $\pi_{r}^{L R^{*}}>\pi_{r}^{N L^{*}}$ and $\pi_{r}^{L R^{*}}>\pi_{r}^{L M^{*}}$ if $T<T^{L R}$, (ii) $\pi_{r}^{N L^{*}}=\pi_{r}^{L R^{*}}=\pi_{r}^{L M^{*}}$ if $T^{L R} \leq T<T^{N L}$, and (iii) $\pi_{r}^{N L^{*}}>\pi_{r}^{L R^{*}}=\pi_{r}^{L M^{*}}$ if $T \geq T^{N L}$.

Proposition 4.4 compares the retailer's expected profits with a small $\beta$ and Figure 3 illustrates the results. If $T<T^{L M}$, when the retailer orders without loan, he orders at most $\frac{T D}{w}$ and he is not able to obtain the optimal 

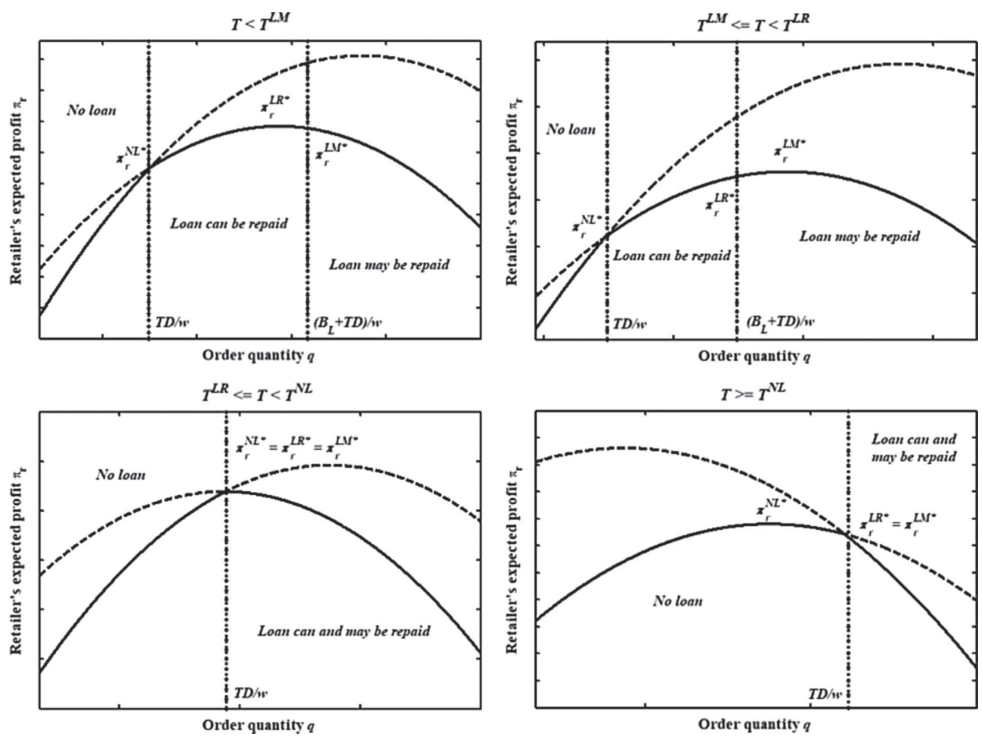

Figure 2. The comparison of retailer's expected profits with a large $\beta$.
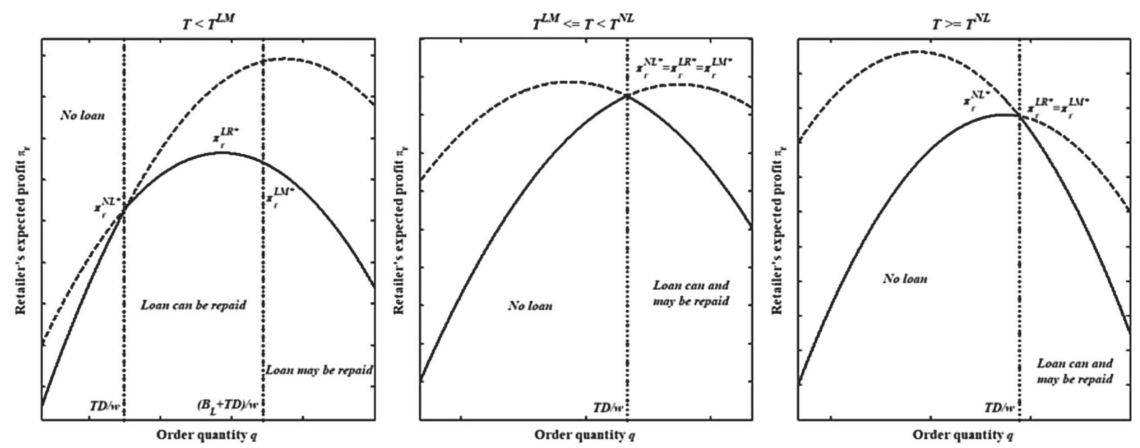

FigURE 3. The comparison of retailer's expected profits with a small $\beta$.

expected profit. By borrowing from a bank, the retailer's expected profit increases because the retailer can order more products from the supplier to satisfy the demand. In addition, a small $\beta$ and a small $T$ correspond to enough revenue from consumers with vouchers $($ i.e. $(p-\beta T) D)$. Therefore, the retailer can repay bank loan and the retailer obtains the maximal expected profit. If the retailer continues to increase his order quantity, he borrows more from a bank with a decreasing expected profit and he may not repay bank loan. If $T^{L M} \leq T<T^{N L}$, the retailer's order quantities are bounded by the constraint of the working capital from voucher sale and then the order quantity is $\frac{T D}{w}$ no matter whether the retailer borrows from a bank or not. If $T \geq T^{N L}$, the retailer does not need to borrow from a bank and he gets the optimal order quantity with no loan to obtain the maximal expected profit.

From Proposition 4.3 and Proposition 4.4, we further obtain Proposition 4.5 to show the impact of voucher's price and voucher's value on the retailer's choice of order quantity.

Proposition 4.5. For $\beta>\hat{\beta}$, (i) $q^{*}=q^{L R}$ if $T<T^{L M}$; (ii) $q^{*}=q^{L M}$ if $T^{L M} \leq T<T^{L R}$; (iii) $q^{*}=\frac{T D}{w}$ if $T^{L R} \leq T<T^{N L}$; and (iv) $q^{*}=q^{N L}$ if $T \geq T^{N L}$. For $\beta \leq \hat{\beta}$, (i) $q^{*}=q^{L R}$ if $T<T^{L R}$; (ii) $q^{*}=\frac{T D}{w}$ if $T^{L R} \leq T<T^{N L}$; and (iii) $q^{*}=q^{N L}$ if $T \geq T^{N L}$. 

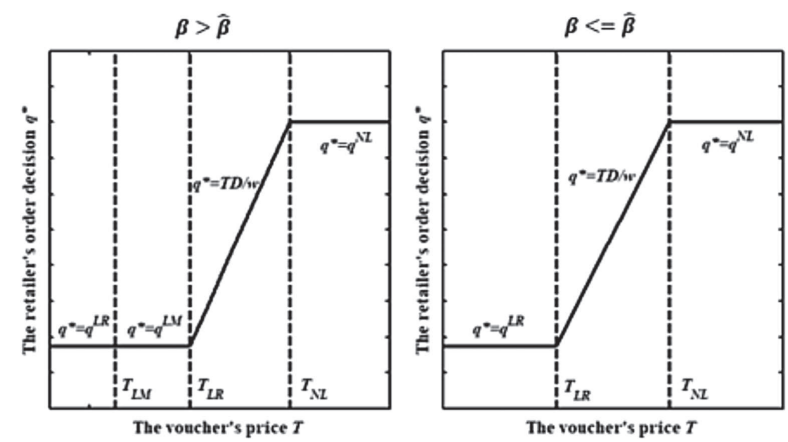

FIGURE 4. The retailer's optimal choice of order quantity.

Proposition 4.5 proposes the retailer's optimal choice of order quantity corresponding to the voucher's price and voucher's value. For $\beta>\hat{\beta}$ as shown in Figure 4 , if $T$ is quite low, the retailer's working capital from demand for vouchers (i.e. $T D$ ) is quite low and then borrowing from a bank is an optimal decision for the retailer. Additionally, a quite low $T$ helps the retailer to repay bank loan because the retailer obtains more revenue from consumers with vouchers (i.e. $(p-\beta T) D)$. Therefore, the retailer obtains more profit from ordering $q^{L R}$ with a quite low $T$ and the loan can be repaid. As $T$ increases to be larger than $T^{L M}$, the retailer's revenue from consumers with vouchers decreases. The retailer still needs to borrow from a bank to order $q^{L M}$ if $T<T^{L R}$, but he cannot make sure whether the loan can be repaid or not. If the voucher's price is not smaller than $T^{L R}$, the retailer does not need to loan from a bank because he obtains more working capital from voucher sale. However, the retailer cannot obtain the optimal order quantity $q^{N L}$ and he orders with all working capital from voucher sale to obtain $\frac{T D}{w}$ if the voucher's price is not larger than $T^{N L}$. For $\beta \leq \hat{\beta}$ as shown in Figure 4, if the voucher's price is larger than $T^{L R}$, the retailer's optimal choice of order quantity is the same as that for $\beta>\hat{\beta}$. If the voucher's price is smaller than $T^{L R}$, the retailer orders $q^{L R}$ and the loan can always be repaid. The reason is that a small $\beta$ corresponds to a small revenue from consumers with vouchers $(i . e .,(p-\beta T) D)$ and then the retailer obtains enough revenue to repay the bank loan.

\subsection{The supplier's decision of wholesale price}

The retailer's choice of order quantity is shown in Proposition 4.5, and the supplier decides her wholesale price by anticipating the retailer's choice of order quantity. As a Stackelberg leader, the supplier's optimization problem can be written as following:

$$
\begin{gathered}
\pi_{s}=w q-c q \\
\text { Subject to: }\left\{\begin{array}{l}
q=q^{*} \\
q \geq D
\end{array} .\right.
\end{gathered}
$$

The supplier provides $q^{*}$ to meet the retailer's order quantity and the supplier's profit is totally from it. Besides, the quantity of products that the supplier provides to the retailer should be larger than $D$ to ensure the retailer to participant in the game. By solving the optimization problem of (4.5), we propose Proposition 4.6 to indicate the supplier's optimal wholesale price $w^{*}$.

Proposition 4.6. The supplier's optimal wholesale price (i) $w^{*}=w^{L}$ if $T<T^{L R}$; (ii) $w^{*}=T$ if $T^{L R} \leq T<$ $T^{N L}$; and (iii) $w^{*}=w^{N L}$ if $T \geq T^{N L}$.

Where $w^{L}$ satisfies pf $\left(F^{-1}\left[1-\frac{w^{L}\left(1+R_{f}\right)}{p}\right]\right) F^{-1}\left[1-\frac{w^{L}\left(1+R_{f}\right)}{p}\right]=\left(w^{L}-c\right)\left(1+R_{f}\right)$ and $w^{N L}$ satisfies $p F^{-1}\left(1-\frac{w^{N L}}{p}\right) f\left[F^{-1}\left(1-\frac{w^{N L}}{p}\right)\right]=w^{N L}-c$. 


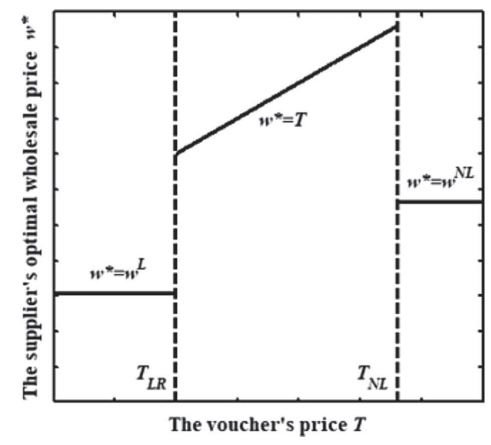

Figure 5. The supplier's optimal wholesale price.

In Proposition 4.6, the supplier's wholesale price is divided into three segments by voucher's price $T$. The reason is that, although the supplier is a Stackelberg leader, her wholesale price is decided by anticipating the retailer's best response to it as shown in Proposition 4.5. If the voucher's price is small (i.e. $\left.T<T^{L R}\right)$, the supplier's wholesale price is $w^{L}$ with the retailer borrowing from a bank. This is because the voucher's price is too small for a retailer to obtain enough working capital to order and by considering it, the supplier would like to decide a wholesale price so that the retailer borrows from a bank. If the voucher's price is larger than $T^{L R}$, the retailer's working capital from voucher sale is larger (i.e. $T D$ ) and his revenue from consumers with vouchers is smaller $(i . e .(p-\beta T) D)$. The supplier would decide a wholesale price so that the retailer orders with all his working capital if the voucher's price is smaller than $T^{N L}$. And if the voucher's price is not smaller than $T^{N L}$, the supplier would notice that it is easy for the retailer to obtain enough working capital from voucher sale. Then the supplier's wholesale price is $w^{N L}$ so that the retailer can obtain the maximal expected profit without borrowing from a bank. Figure 5 illustrates the results.

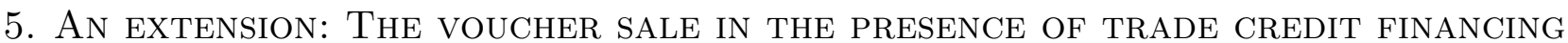

In the previous sections, we examined the voucher sale as a financing source in a capital-constrained supply chain by considering bank financing as a supplementary source. This is widely used that an online platform serves as an intermediary role to sell vouchers of a product [18] and to offer an access to bank for the capitalconstrained firms [22]. In practice, trade credit financing is also an important form of financing for firms especially in economies with less developed financial markets or weak bank-firm relationships [5].

This section considers the voucher sale in the presence of trade credit financing. Similar to the work of Kouvelis and Zhao [25] and Chen [5], we assume that the contract variable is the "postponed" wholesale price $w_{C}=w\left(1+r_{C}\right)$ where $C$ represents trade credit financing. For the case that the retailer does not adopt trade credit financing, the firms' optimization problem is the same as that of the case without loan from a bank in Subsection 4.1. For the case that the retailer adopts trade credit financing, the retailer's optimization problem is formulated as (5.1) in the condition that the financing can be repaid.

$$
\begin{aligned}
& \pi_{r}^{C R}=(p-\beta T) D+p E \min [q-D,(\alpha-1) D]-\left(w_{C} q-T D\right) \\
& \text { Subject to: }\left\{\begin{aligned}
w_{C} q & >T D \\
(p-\beta T) D & \geq w_{C} q-T D . \\
q & \geq D
\end{aligned}\right.
\end{aligned}
$$

It is interesting to notice that the objective function in (5.1) is the same as that in (4.1), which is also the optimization problem of the case without adopting trade credit financing. The first constraint in (5.1) is that the retailer's working capital from voucher sale $T D$ does not cover the payment on ordering $w_{C} q$. Then there is a capital gap $w_{C} q-T D$ for the retailer to finance by trade credit, and with the financing can be repaid, the 
retailer's revenue from consumers with vouchers is larger than the capital gap, which is shown as the second constraint in (5.1). Besides, the retailer's order quantity is at least $D$ to satisfy the consumers with vouchers, i.e. $q \leq D$.

In the condition that the trade credit financing may be repaid, the retailer's optimization problem is

$$
\begin{aligned}
\pi_{r}^{C M}=E\left\{(p-\beta T) D+p \min [q-D,(\alpha-1) D]-\left(w_{C} q-T D\right)\right\}^{+} \\
\text {Subject to: }\left\{\begin{array}{c}
w_{C} q>T D \\
(p-\beta T) D<w_{C} q-T D . \\
q \geq D
\end{array}\right.
\end{aligned}
$$

The retailer may obtain zero expected profit in this condition. Similar to the condition that the trade credit financing can be repaid, there is a capital gap $w_{C} q-T D$ for the retailer to finance by trade credit. As shown in the second constraint, the retailer's revenue from consumers with vouchers does not cover the capital gap, and it is consistent to that the retailer would not know whether he can repay the trade credit financing or not. In addition, the retailer needs to order at least $D$ to satisfy the consumers with vouchers as shown in the third constraint.

In the presence of trade credit financing, Lemma 5.1 shows the possible optimal order quantities for a given $w_{C}$ by considering the voucher's price.

Lemma 5.1. In the present of trade credit financing, when the retailer does not adopt the financing, (i) $q^{N R^{*}}=$ $q^{N R}$ if $T \geq \widetilde{w}_{C}$ and (ii) $q^{N R^{*}}=\frac{T D}{w_{C}}$ if $T<\widetilde{w}_{C}$; when the financing can be repaid, (i) $q^{C R^{*}}=\frac{T D}{w_{C}}$ if $T \geq \widetilde{w}_{C}$ (ii) $q^{C R^{*}}=q^{C R}$ if $T<\widetilde{w}_{C}$ and $T \leq \frac{p-\tilde{w}_{C}}{\beta-1}$, (iii) $q^{C R^{*}}=\frac{(p-\beta T) D+T D}{w_{C}}$ if $T<\tilde{w}_{C}$ and $T>\frac{p-\tilde{w}_{C}}{\beta-1}$; when the financing may be repaid, (i) $q^{C M^{*}}=\frac{T D}{w_{C}}$ if $T \geq \frac{w_{C} q^{C M}}{D}$, (ii) $q^{C M^{*}}=q^{C M}$ if $T<\frac{w_{C} q^{C M}}{D}$ and $T>\frac{p D-w_{C} q^{C M}}{D(\beta-1)}$, (iii) $q^{C M^{*}}=\frac{(p-\beta T) D+T D}{w_{C}}$ if $T<\frac{w_{C} q^{C M}}{D}$ and $T \leq \frac{p D-w_{C} q^{C M}}{D(\beta-1)}$.

Where $\tilde{w}_{C}=w_{C} F^{-1}\left(1-\frac{w_{C}}{p}\right), q^{N R}=q^{C R}=D F^{-1}\left(1-\frac{w_{C}}{p}\right)$ and $q^{C M}$ satisfies $p \bar{F}\left(\frac{q^{C M}}{D}\right)=$ $w_{C} \bar{F}\left(\frac{\beta T D-T D+w_{C} q^{C M}}{p D}\right)$.

When the retailer does not adopt trade credit financing, the retailer obtains enough capital to get the optimal order quantity if the voucher's price is large (i.e. $T \geq w_{C} F^{-1}\left(1-\frac{w_{C}}{p}\right)$ ). However, the optimal order quantity is not obtained if the voucher's price is small $\left(\right.$ i.e. $\left.T<w_{C} F^{-1}\left(1-\frac{w_{C}}{p}\right)\right)$ and therefore, the retailer orders with all revenue from voucher sale. When the retailer adopts trade credit financing and if it can be repaid, the retailer orders with all revenue from voucher sale with a quite large voucher price $\left(i . e . T \geq w_{C} F^{-1}\left(1-\frac{w_{C}}{p}\right)\right)$. If the voucher's price is not quite large (i.e. $T<w_{C} F^{-1}\left(1-\frac{w_{C}}{p}\right)$ ), the retailer obtains the optimal order quantity if the voucher's price also satisfies $T \leq \frac{p-w_{C} F^{-1}\left(1-\frac{w_{C}}{p}\right)}{\beta-1}$; otherwise, the retailer's payment on ordering equals to total revenues from voucher sale and consumers with vouchers. When the retailer adopts trade credit financing and it can be repaid, the retailer orders with revenue from voucher sale if the voucher's price is larger than $\frac{w_{C} q^{C M}}{D}$. If the voucher's price is smaller than $\frac{w_{C} q^{C M}}{D}$, the retailer obtains the optimal order quantity when the voucher's price is also larger than $\frac{p D-w_{C} q^{C M}}{D(\beta-1)}$; while when the voucher's price is smaller than $\frac{p D-w_{C} q^{C M}}{D(\beta-1)}$, the retailer's payment on ordering equals to total revenues from voucher sale and consumers with vouchers.

Furthermore, we demonstrate the retailer's optimal choice of order quantity in the presence of trade credit financing in Proposition 5.2.

Proposition 5.2. The retailer's optimal choice of order quantity in the presence of trade credit financing is $q^{C^{*}}$ : (i) for $\beta<\frac{p D}{w_{C} q^{C M}}, q^{C^{*}}=q^{C R}$ if $T<\tilde{w}_{C}, q^{C^{*}}=q^{N R}$ if $T \geq \widetilde{w}_{C}$; (ii) for $\frac{p D}{w_{C} q^{C M}} \leq \beta<\frac{p D}{w_{C} q^{N R}}, \quad q^{C^{*}}=q^{C R}$ if $T<\widetilde{w}_{C}, q^{C^{*}}=q^{N R}$ if $\tilde{w}_{C} \leq T<\frac{p D-w_{C} q^{C M}}{D(\beta-1)}, q^{C^{*}}=q^{C M}$ if $\frac{p D-w_{C} q^{C M}}{D(\beta-1)} \leq T<\frac{w_{C} q^{C M}}{D}, q^{C^{*}}=q^{N R}$ if $T \geq \frac{w_{C} q^{C M}}{D}$; (iii) for $\beta \geq \frac{p D}{w_{C} q^{N R}}, \quad q^{C^{*}}=q^{C R}$ if $T<\frac{p D-w_{C} q^{C M}}{D(\beta-1)}, q^{C^{*}}=q^{C M}$ if $\frac{p D-w_{C} q^{C M}}{D(\beta-1)} \leq T<$ $\frac{w_{C} q^{C M}}{D}, q^{C^{*}}=q^{N R}$ if $T \geq \frac{w_{C} q^{C M}}{D}$. 


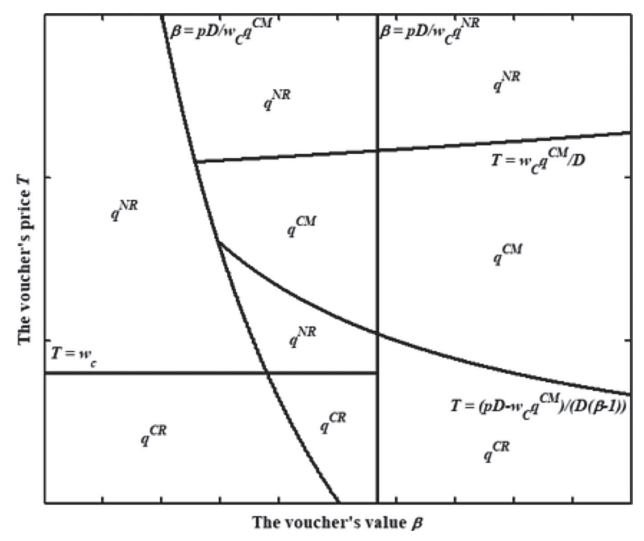

FIgURE 6. The retailer's optimal choice of order quantity.

The retailer's optimal choice of order quantity with voucher sale in the presence of trade credit financing is shown in Proposition 5.2. For a small $\beta$ (i.e. $\left.\beta<\frac{p D}{w_{C} q^{C M}}\right)$, if the voucher's price is small $\left(i . e . T<\widetilde{w}_{C}\right)$, the retailer needs to borrow from the supplier because his working capital $T D$ is small but he can repay the trade credit financing because his revenue from consumers with vouchers $(p-\beta T) D$ is large. As a result, the retailer's optimal choice of order quantity is $q^{C R}$. If the voucher's price is large, the retailer obtains enough working capital $T D$ to order from the supplier and his order quantity is $q^{N R}$. For a medium $\beta$ (i.e. $\left.\frac{p D}{w_{C} q^{C M}} \leq \beta<\frac{p D}{w_{C} q^{N R}}\right)$, the retailer needs to borrow from the supplier if $T<\widetilde{w}_{C}$ because his working capital $T D$ is not large enough. Meanwhile, the trade credit financing can be repaid as result of the retailer's revenue from consumers with vouchers $(p-\beta T) D$ being large enough. If the voucher's price is larger than $\widetilde{w}_{C}$, the retailer's working capital becomes large enough to order without borrowing from the supplier and his optimal choice of order quantity is $q^{N R}$. However, the retailer would notice that it is more profitable to borrow from the supplier to order $q^{C M}$ by taking some risk that the trade credit financing may not be repaid if $\frac{p D-w_{C} q^{C M}}{D(\beta-1)} \leq T<\frac{w_{C} q^{C M}}{D}$. The reason is that, by borrowing from the supplier, the retailer obtains more order quantity to satisfy the consumers and the risk is undertaken by the supplier. For a large $\beta$ (i.e. $\left.\beta \geq \frac{p D}{w_{C} q^{N R}}\right)$, if the voucher's price is smaller than $\frac{w_{C} q^{C M}}{D}$, the retailer needs to borrow from the supplier to order. With a voucher's price smaller than $\frac{p D-w_{C} q^{C M}}{D(\beta-1)}$, the retailer's revenue from consumers with vouchers $(p-\beta T) D$ is large enough for the retailer to repay the trade credit financing, while the trade credit financing may be repaid if the voucher's price is larger than $\frac{p D-w_{C} q^{C M}}{D(\beta-1)}$. If the voucher's price is larger than $\frac{w_{C} q^{C M}}{D}$, the retailer obtains enough working capital $T D$ from voucher sale to order without borrowing from the supplier. Figure 6 shows the results.

We obtain the retailer's optimal choice of order quantity in Proposition 5.2 for a given wholesale price by considering the voucher's price and voucher's value. Next, we analyze the supplier's optimal wholesale price in the presence of trade credit financing. Considering the retailer's best response to the supplier's wholesale price, the supplier's optimization problem is

$$
\begin{gathered}
\pi_{s}^{c}=E \min \left\{w_{c} q,(p-\beta T) D+p \min [q-D,(\alpha-1) D]+T D\right\}-c q \\
\text { Subject to: }\left\{\begin{array}{c}
q=q^{C^{*}} \\
q \geq D
\end{array}\right.
\end{gathered}
$$

In (5.3), the supplier may obtain the full payment $w_{C} q$ from the retailer or the retailer's total revenue $(p-\beta T) D+p \min [q-D,(\alpha-1) D]+T D$. The supplier should provide $q^{C M^{*}}$ to the retailer as shown in Proposition 5.2 and the order quantity should be at least $D$ so that the retailer would engage in the game. Proposition 5.3 summarizes the supplier's optimal wholesale price. 


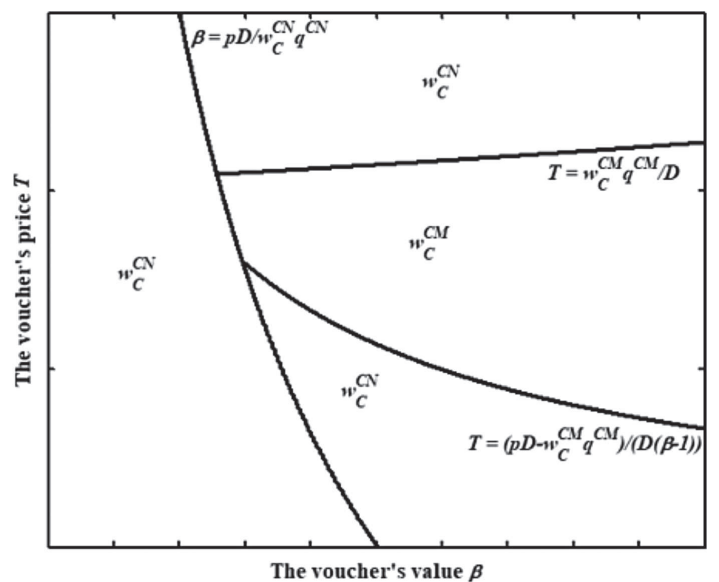

FiguRE 7. The supplier's optimal wholesale price.

Proposition 5.3. The supplier s optimal wholesale price in the presence of trade credit financing is $w_{C}^{*}:(i)$ for $\beta<\frac{p D}{w^{C N} q^{C M}}, \quad w_{C}^{*}=w_{C}^{C N}$, (ii) for $\beta \geq \frac{p D}{w^{C N} q^{C M}}, \quad w_{C}^{*}=w_{C}^{C N}$ if $T<\frac{p D-w_{C}^{C M} q^{C M}}{D(\beta-1)}, w_{C}^{*}=w_{C}^{C M}$ if $\frac{p D-w_{C}^{C M} q^{C M}}{D(\beta-1)} \leq T<\frac{w_{C}^{C M} q^{C M}}{D}$, and $w_{C}^{*}=w_{C}^{C N}$ if $T \geq \frac{w_{C}^{C M} q^{C M}}{D}$.

Where $w_{C}^{C N}$ satisfies $p f\left[F^{-1}\left(1-\frac{w_{C}^{C N}}{p}\right)\right] F^{-1}\left(1-\frac{w_{C}^{C N}}{p}\right)=w_{C}^{C N}-c$ and $w_{C}^{C M}$ satisfies $c p D+$ $p^{2} q^{C M} f\left(\frac{q^{C M}}{D}\right)-p^{2} D \bar{F}\left(\frac{q^{C M}}{D}\right)=c w_{C}^{C M} q^{C M} \frac{f\left(\frac{\beta T D-T D+w_{C}^{C M} q^{C M}}{p D}\right)}{\bar{F}\left(\frac{\beta T D-T D+w_{C}^{C M} q^{C M}}{p D}\right)}$.

For a small $\beta$ (i.e. $\beta<\frac{p D}{w^{C N} q^{C M}}$ ), the supplier would always set the wholesale price at $w^{C N}$. This is because the retailer obtains enough revenue $(p-\beta T) D$ from consumers with vouchers when $\beta$ is small and whether the retailer borrows from the supplier or not, the trade credit financing can be repaid. Therefore, the supplier's wholesale price is $w^{C N}$ by considering the response of the retailer. For a large $\beta$ (i.e. $\beta \geq \frac{p D}{w^{C N} q^{C M}}$ ), the supplier anticipates that the retailer would order a quantity that he may not repay the trade credit financing if $\frac{p D-w_{C}^{C M} q^{C M}}{D(\beta-1)} \leq T<\frac{w_{C}^{C M} q^{C M}}{D}$. As a result, the supplier's wholesale price is $w_{C}^{C M}$ in this condition. Otherwise, the supplier anticipates that the retailer would order with his working capital or order with the trade credit financing can be repaid. Then the supplier's wholesale price is $w_{C}^{C N}$. Figure 7 shows the results.

\section{Conclusion}

In this paper, we have studied the role of voucher sale on operation of a supply chain which consists of a supplier and a capital-constrained retailer. We assume that the retailer raises working capital by voucher sale before ordering and from the sale of vouchers, the retailer not only raises working capital but also can predict the revenue from consumers with vouchers. We analyze the retailer's optimal choice of order quantity in the cases without and with loan from a bank and specifically, the case with loan from a bank includes the conditions that loan can and may be repaid. The supplier's optimal wholesale price is derived by anticipating the retailer's best response to it. Furthermore, we show the impact of voucher sale with trade credit financing on the retailer's choice of order quantity and the supplier's decision of wholesale price.

Our analysis shows that the retailer obtains more by borrowing from a bank if the voucher's price is small; otherwise, it is optimal for the retailer not to borrow from a bank. The voucher's value corresponds to the retailer's revenue from consumers with vouchers, which has an impact on whether the retailer can or may repay 
the bank loan. For a large voucher's value, the retailer earns most by borrowing from a bank and he can repay the bank loan if the voucher's price is small too. While if the voucher's price is larger, the retailer borrows more from a bank to earn more profit and he may not repay the bank loan. For a small voucher's value, the retailer obtains most by borrowing from a bank to order and he can repay the bank, or by not borrowing from a bank. As to the supplier, if voucher's price is large, the supplier makes an optimal wholesale price decision which leads the retailer not to borrow from a bank; and if voucher's price is small, the supplier's optimal decision is obtained by anticipating the retailer to borrow from a bank. In the presence of trade credit financing, when the voucher's price is quite large, the retailer would not borrow from the supplier. If the voucher's price is not quite large, the retailer borrows from the supplier and the financing can be repaid with a small voucher's value. If voucher's value is large, the voucher's price should be also small so that the retailer can repay the supplier; otherwise, the retailer either does not borrow from the supplier or may not repay the supplier. The supplier would decide a wholesale price so that the retailer does not borrow or can repay the supplier, except that the voucher's value is large and the voucher's price is medium.

The managerial implication of the paper is that the retailer and the supplier would make their best choices by observing the voucher's price and voucher's value. For the retailer, he would notice whether he should borrow from a bank or not by considering the voucher's price. Specifically, if the voucher's price is quite large, it is optimal for him not to borrow from a bank to order; otherwise, his best choice is to borrow from a bank. Besides, by observing both the voucher's price and voucher's value, the retailer would realize whether it is profitable for him to take some risk that the loan may not be repaid. For a large voucher's value, the retailer would get that he may not repay the bank loan if the voucher's price is not quite large. While for a small voucher's value, the retailer can always repay the loan if he borrows from a bank. The supplier would make her wholesale price decision by anticipating that the retailer does not borrow from a bank or can repay the bank loan if the voucher's value is small. However, the supplier would take both the voucher's price and voucher's value into consideration to anticipate whether the retailer can or may repay the bank loan to make her wholesale price decision. Similar to the firms' decisions with voucher sale in the presence of bank financing, the retailer's optimal choice of order quantity and the supplier's decision of wholesale price are reflected by the voucher's price and voucher's value in the presence of trade credit financing.

This paper has several potential extensions. First, our model assumes that consumers buying vouchers do not give up buying products in holiday and the total demand is characterized by a random variable. However, some consumers buying vouchers may not buy products and some price-sensitive consumers may be attracted to buy products which would have an impact on the total demand [23,29]. Second, to focus on the impact of voucher sale, we assume the retailer's expenditures of voucher sale and borrowing from a bank through an online platform are both zero, and there is no bankruptcy cost for the retailer. However, an online platform may charge for its service and the retailer needs to pay bankruptcy cost, therefore the existence of expenditures from an online platform and bankruptcy cost can be considered in future research $[16,25,35]$. Third, it is assumed that the retailer borrows from a bank through an online platform with risk-free interest. In practice, a bank with risk-free interest may loan to the online platform and then the online platform loans to capital-constrained firms by maximizing its profit $[34,41]$.

\section{Appendix A.}

Proof of Lemma 4.1. The objective function of (4.1) is reduced to $\pi_{r}^{N L}=p q-\beta T D-p D \int_{u}^{\frac{q}{D}} F(\alpha) d \alpha-w q+T D$. We get $\frac{d \pi_{r}^{N L}}{d q}=p-p F\left(\frac{q}{D}\right)-w$ and $\frac{d^{2} \pi_{r}^{N L}}{d q^{2}}=-\frac{p}{D} f\left(\frac{q}{D}\right)<0$. Let $\frac{d \pi_{r}^{N L}}{d q}=0$ and then optimal $q^{N L}$ satisfies $p-p F\left(\frac{q^{N L}}{D}\right)-w=0$. So $q^{N L}=D F^{-1}\left(1-\frac{w}{p}\right)$ is the unique optimal solution for the objective function of (4.1).

Considering the first constraint in (4.1), we get that, if $q^{N L} \leq \frac{T D}{w}, q^{N L^{*}}=q^{N L}$; and if $q^{N L}>\frac{T D}{w} q^{N L^{*}}=$ $\frac{T D}{w} \cdot q^{N L} \leq \frac{T D}{w}$ is further reduced to $T \geq w F^{-1}\left(1-\frac{w}{p}\right)$ and $q^{N L}>\frac{T D}{w}$ is reduced to $T<w F^{-1}\left(1-\frac{w}{p}\right)$. 
Therefore, if $T \geq w F^{-1}\left(1-\frac{w}{p}\right), q^{N L^{*}}=q^{N L}$; and if $T<w F^{-1}\left(1-\frac{w}{p}\right), q^{N L^{*}}=\frac{T D}{w}$. Considering the second constraint in (4.1), if $T \geq w F^{-1}\left(1-\frac{w}{p}\right), q^{N L^{*}}=q^{N L} \geq D$ and it is reduced to $D F^{-1}\left(1-\frac{w}{p}\right) \geq D$ which always exist for $1-\frac{w}{p} \geq F(1)=F(u)=0$; and if $T<w F^{-1}\left(1-\frac{w}{p}\right), q^{N L^{*}}=\frac{T D}{w} \geq D$ and it is reduced to $w \leq T$.

Proof of Lemma 4.2. In the condition that the loan can be repaid, the retailer's working capital from consumers with vouchers $(p-\beta T) D$ is not smaller than $B\left(1+R_{f}\right)$ as it is shown in the second constraint of (4.3). For $R_{b}=R_{f}$, the objective function of (4.3) is reduced to

$$
\pi_{r}^{L R}=p q-\beta T D-p D \int_{u}^{\frac{q}{D}} F(\alpha) \mathrm{d} \alpha-B\left(1+R_{f}\right) .
$$

The first-order condition of $\pi_{r}^{L R}$ with respect to $q$ is $\frac{\mathrm{d} \pi_{r}^{L R}}{\mathrm{~d} q}=p-p F\left(\frac{q}{D}\right)-w\left(1+R_{f}\right)$ and $\frac{\mathrm{d}^{2} \pi_{r}^{L R}}{\mathrm{~d} q^{2}}=$ $-\frac{p}{D} f\left(\frac{q}{D}\right)<0$. Then the optimal $q$ satisfies $\frac{\mathrm{d} \pi_{r}^{L R}}{\mathrm{~d} q}=0$ and we get $q^{L R}=D F^{-1}\left[1-\frac{w\left(1+R_{f}\right)}{p}\right]$. By satisfying the first two constraints of (4.3) and $\frac{\mathrm{d}^{2} \pi_{r}^{L R}}{\mathrm{~d} q^{2}}<0$, we get that if $w q^{L R} \leq T D\left(\right.$ i.e. $\left.T \geq w F^{-1}\left[1-\frac{w\left(1+R_{f}\right)}{p}\right]\right)$, $q^{L R^{*}}=\frac{T D}{w}$; if $w q^{L R}>T D$ and $(p-\beta T) D \geq\left(w q^{L R}-T D\right)\left(1+R_{f}\right)$ (i.e. $T<w F^{-1}\left[1-\frac{w\left(1+R_{f}\right)}{p}\right]$ and $\left.\frac{p-\beta T}{1+R_{f}}+T \geq w F^{-1}\left[1-\frac{w\left(1+R_{f}\right)}{p}\right]\right), q^{L R^{*}}=q^{L R}$ and if $w q^{L R}>T D$ and $(p-\beta T) D<\left(w q^{L R}-T D\right)\left(1+R_{f}\right)$ (i.e. $T<w F^{-1}\left[1-\frac{w\left(1+R_{f}\right)}{p}\right]$ and $\left.\frac{p-\beta T}{1+R_{f}}+T<w F^{-1}\left[1-\frac{w\left(1+R_{f}\right)}{p}\right]\right), q^{L R^{*}}=\frac{B_{L}}{w}+\frac{T D}{w}$. By satisfying the third constraint of (4.3), if $T \geq w F^{-1}\left[1-\frac{w\left(1+R_{f}\right)}{p}\right], \frac{T D}{w} \geq D$ and then $w \leq T$; if $T<w F^{-1}\left[1-\frac{w\left(1+R_{f}\right)}{p}\right]$ and $\frac{p-\beta T}{1+R_{f}}+T \geq w F^{-1}\left[1-\frac{w\left(1+R_{f}\right)}{p}\right], \quad q^{L R}=D F^{-1}\left[1-\frac{w\left(1+R_{f}\right)}{p}\right] \geq D$ and it always exists; if $T<$ $w F^{-1}\left[1-\frac{w\left(1+R_{f}\right)}{p}\right]$ and $\frac{p-\beta T}{1+R_{f}}+T<w F^{-1}\left[1-\frac{w\left(1+R_{f}\right)}{p}\right], \frac{B_{L}}{w}+\frac{T D}{w} \geq D$ and then $w \leq \frac{p-\beta T}{1+R_{f}}+T$.

In the condition that the loan may be repaid, then $(p-\beta T) D<B\left(1+R_{f}\right)$ is satisfied as shown in the second constraint of (4.4). The objective function of (4.4) is reduced to

$$
\pi_{r}^{L M}=p q-\beta T D-p D \int_{u}^{\frac{q}{D}} F(\alpha) \mathrm{d} \alpha-E \min \left\{B\left(1+R_{b}\right), p \min [q-D,(\alpha-1) D]+(p-\beta T) D\right\} .
$$

$B\left(1+R_{f}\right)=E \min \left\{B\left(1+R_{b}\right), p \min [q-D,(\alpha-1) D]+(p-\beta T) D\right\}$ as shown in equation (4.2), we get $\pi_{r}^{L M}$ 's first-order condition with respect to $q$ is $\frac{\mathrm{d} \pi_{r}^{L M}}{\mathrm{~d} q}=p-p F\left(\frac{q}{D}\right)-w\left(1+R_{f}\right)$. The second order condition is $\frac{\mathrm{d}^{2} \pi_{r}^{L M}}{\mathrm{~d} q^{2}}=-\frac{p}{D} f\left(\frac{q}{D}\right)<0$. Then we get the unique optimal solution $q^{L M}=$ $D F^{-1}\left[1-\frac{w\left(1+R_{f}\right)}{p}\right]$. From the first two constraints of (4.4), we get that if $w q^{L M} \leq T D$ (i.e. T $\geq$ $\left.w F^{-1}\left[1-\frac{w\left(1+R_{f}\right)}{p}\right]\right), \quad q^{L M^{*}}=\frac{T D}{w}$; if $w q^{L M}>T D$ and $(p-\beta T) D<\left(w q^{L M}-T D\right)\left(1+R_{f}\right)$ (i.e. $T<w F^{-1}\left[1-\frac{w\left(1+R_{f}\right)}{p}\right]$ and $\left.\frac{p-\beta T}{1+R_{f}}+T<w F^{-1}\left[1-\frac{w\left(1+R_{f}\right)}{p}\right]\right), \quad q^{L M^{*}}=q^{L M}$; and if $w q^{L M}>T D$ and $(p-\beta T) D \geq\left(w q^{L M}-T D\right)\left(1+R_{f}\right) \quad\left(\right.$ i.e. $T<w F^{-1}\left[1-\frac{w\left(1+R_{f}\right)}{p}\right]$ and $\left.\frac{p-\beta T}{1+R_{f}}+T \geq w F^{-1}\left[1-\frac{w\left(1+R_{f}\right)}{p}\right]\right)$, $q^{L M^{*}}=\frac{B_{L}}{w}+\frac{T D}{w}$. By satisfying the third constraint of (4.4), if $T \geq w F^{-1}\left[1-\frac{w\left(1+R_{f}\right)}{p}\right], \frac{T D}{w} \geq D$ and then $w \leq T$; if $T<w F^{-1}\left[1-\frac{w\left(1+R_{f}\right)}{p}\right]$ and $\frac{p-\beta T}{1+R_{f}}+T<w F^{-1}\left[1-\frac{w\left(1+R_{f}\right)}{p}\right], q^{L M}=D F^{-1}\left[1-\frac{w\left(1+R_{f}\right)}{p}\right] \geq D$ and it always exists; and if $T<w F^{-1}\left[1-\frac{w\left(1+R_{f}\right)}{p}\right]$ and $\frac{p-\beta T}{1+R_{f}}+T \geq w F^{-1}\left[1-\frac{w\left(1+R_{f}\right)}{p}\right], \frac{B_{L}}{w}+\frac{T D}{w} \geq D$ and then $w \leq \frac{p-\beta T}{1+R_{f}}+T$. 
Proof of Proposition 4.3. From Lemma 4.1, we obtain that if $T \geq T^{N L}, q^{N L^{*}}=q^{N L}$; otherwise, $q^{N L^{*}}=\frac{T D}{w}$ in the case without loan from a bank. And from Lemma 4.2, in the case with loan from a bank, we obtain that if $T \geq T^{L R}, q^{L R^{*}}=q^{L M^{*}}=\frac{T D}{w}$; if $T<T^{L R}$ and $T \leq T^{L M}, q^{L R^{*}}=q^{L R}$; if $T<T^{L R}$ and $T>T^{L M}$, $q^{L R^{*}}=\frac{B_{L}}{w}+\frac{T D}{w}$; if $T<T^{L R}$ and $T \geq T^{L M}, q^{L M^{*}}=q^{L M}$; and if $T<T^{L R}$ and $T<T^{L M}, q^{L M^{*}}=\frac{B_{L}}{w}+\frac{T D}{w}$. For a large voucher's value $\beta>\hat{\beta}$, we obtain $T^{L M}<T^{L R}<T^{N L}$.

If $T<T^{L M}$, the retailer's optimal order quantities are $q^{N L^{*}}=\frac{T D}{w}, q^{L R^{*}}=q^{L R}$, and $q^{L M^{*}}=\frac{B_{L}}{w}+\frac{T D}{w}$. We notice that $\pi_{r}^{L R}\left(\frac{T D}{w}\right)=\pi_{r}^{N L}\left(\frac{T D}{w}\right)$ from the expected profit function of $\pi_{r}^{L R}$ and $\pi_{r}^{N L}$. We obtain $\pi_{r}^{L R}\left(q^{L R}\right)>$ $\pi_{r}^{L R}\left(\frac{B_{L}}{w}+\frac{T D}{w}\right)$ and $\pi_{r}^{L R}\left(q^{L R}\right)>\pi_{r}^{L R}\left(\frac{T D}{w}\right)$ for $q^{L R}$ is optimal solution of $\pi_{r}^{L R}$. Thus, $\pi_{r}^{L R^{*}}>\pi_{r}^{N L^{*}}$ and $\pi_{r}^{L R^{*}}>\pi_{r}^{L M^{*}}$

If $T^{L M} \leq T<T^{L R}$, the retailer's optimal order quantities are $q^{N L^{*}}=\frac{T D}{w}, q^{L R^{*}}=\frac{B_{L}}{w}+\frac{T D}{w}$ and $q^{L M^{*}}=q^{L M}$. We obtain $\pi_{r}^{N L}\left(\frac{T D}{w}\right)=\pi_{r}^{L R}\left(\frac{T D}{w}\right)$ from expected profit function of $\pi_{r}^{N L}$ and $\pi_{r}^{L R}$. Because $\pi_{r}^{L R}(q)=\pi_{r}^{L M}(q)$ for any $q, \pi_{r}^{L R}\left(q^{L R}\right)=\pi_{r}^{L M}\left(q^{L M}\right) \cdot \pi_{r}^{L R}\left(q^{L R}\right)>\pi_{r}^{L R}\left(\frac{T D}{w}\right)$ and $\pi_{r}^{L R}\left(q^{L R}\right)>\pi_{r}^{L R}\left(\frac{B_{L}}{w}+\frac{T D}{w}\right)$ are satisfied because $q^{L R}$ is optimal solution of $\pi_{r}^{L R}$. Then we get $\pi_{r}^{L M}\left(q^{L M}\right)>\pi_{r}^{N L}\left(\frac{T D}{w}\right)$ and $\pi_{r}^{L M}\left(q^{L M}\right)>\pi_{r}^{L R}\left(\frac{B_{L}}{w}+\frac{T D}{w}\right)$. That is $\pi_{r}^{L M^{*}}>\pi_{r}^{N L^{*}}$ and $\pi_{r}^{L M^{*}}>\pi_{r}^{L R^{*}}$.

If $T^{L R} \leq T<T^{N L}$, the retailer's optimal order quantities are $q^{N L^{*}}=\frac{T D}{w}, q^{L R^{*}}=\frac{T D}{w}$ and $q^{L M^{*}}=\frac{T D}{w}$. Notice that $\pi_{r}^{N L}\left(\frac{T D}{w}\right)=\pi_{r}^{L R}\left(\frac{T D}{w}\right)=\pi_{r}^{L M}\left(\frac{T D}{w}\right)$ from the objective function of (4.1), and (4.4). Therefore $\pi_{r}^{L M^{*}}=\pi_{r}^{N L^{*}}=\pi_{r}^{N L^{*}}$ is obtained.

If $T \geq T^{N L}$, the retailer's optimal order quantities are $q^{N L^{*}}=q^{N L}, q^{L R^{*}}=\frac{T D}{w}$ and $q^{L M^{*}}=\frac{T D}{w}$. Notice that $q^{N L}$ is the optimal order quantity of $\pi_{r}^{N L}, \pi_{r}^{N L}\left(q^{N L}\right)>\pi_{r}^{N L}\left(\frac{T D}{w}\right)$ is satisfied. In addition, we obtain $\pi_{r}^{N L}\left(\frac{T D}{w}\right)=\pi_{r}^{L R}\left(\frac{T D}{w}\right)=\pi_{r}^{L M}\left(\frac{T D}{w}\right)$ from the objective function of equations (4.1), (4.3) and (4.4). Then we get $\pi_{r}^{N L}\left(q^{N L}\right)>\pi_{r}^{L R}\left(\frac{T D}{w}\right)=\pi_{r}^{L M}\left(\frac{T D}{w}\right)$ and then $\pi_{r}^{N L^{*}}>\pi_{r}^{L R^{*}}=\pi_{r}^{L M^{*}}$.

Proof of Proposition 4.4. For a voucher's value satisfying $\beta \leq \hat{\beta}, T^{L R}<T^{L M}<T^{N L}$ or $T^{L R}<T^{N L}<T^{L M}$ is obtained by simple calculation. For $T^{L R}<T^{L M}<T^{N L}$ and $T^{L R}<T^{N L}<T^{L M}$, if $T<T^{L R}$, the retailer can order $q^{N L^{*}}=\frac{T D}{w}$ with no loan, $q^{L R^{*}}=q^{L R}$ with loan can be repaid and $q^{L M^{*}}=\frac{B_{L}}{w}+\frac{T D}{w}$ with loan may be repaid. We know, from the objective functions of (4.1), (4.3) and (4.4), that $\pi_{r}^{N L}{ }^{w}\left(\frac{T D}{w}\right) \stackrel{w}{=} \pi_{r}^{L R}\left(\frac{T D}{w}\right)$ and $\pi_{r}^{L R}(q)=\pi_{r}^{L M}(q)$ for any $q$. From $\pi_{r}^{L R}(q)=\pi_{r}^{L M}(q)$, we get $\pi_{r}^{L R}\left(\frac{B_{L}}{w}+\frac{T D}{w}\right)=\pi_{r}^{L M}\left(\frac{B_{L}}{w}+\frac{T D}{w}\right)$. $q^{L R}$ is optimal solution of $\pi_{r}^{L R}$, we get $\pi_{r}^{L R}\left(q^{L R}\right)>\pi_{r}^{L R}\left(\frac{T D}{w}\right)$ and $\pi_{r}^{L R}\left(q^{L R}\right)>\pi_{r}^{L R}\left(\frac{B_{L}}{w}+\frac{T D}{w}\right)$. Then we get $\pi_{r}^{L R}\left(q^{L R}\right)>\pi_{r}^{N L}\left(\frac{T D}{w}\right)$ and $\pi_{r}^{L R}\left(q^{L R}\right)>\pi_{r}^{L M}\left(\frac{B_{L}}{w}+\frac{T D}{w}\right)$. That is $\pi_{r}^{L R^{*}}>\pi_{r}^{N L^{*}}$ and $\pi_{r}^{L R^{*}}>\pi_{r}^{L M^{*}}$.

If $T^{L R} \leq T<T^{N L}$, ordering $q^{N L^{*}}=\frac{T D}{w}$ with no loan, $q^{L R^{*}}=\frac{T D}{w}$ with loan can be repaid and $q^{L M^{*}}=$ $\frac{T D}{w}$ with loan may be repaid are the retailer's order quantities. It is obvious that $\pi_{r}^{N L}\left(\frac{T D}{w}\right)=\pi_{r}^{L R}\left(\frac{T D}{w}\right)=$ $\pi_{r}^{L M}\left(\frac{T D}{w}\right)$ from objective functions of $(4.1),(4.3)$ and (4.4). Therefore, we get $\pi_{r}^{N L^{*}}=\pi_{r}^{L R^{*}}=\pi_{r}^{L M^{*}}$.

If $T \geq T^{N L}$, the retailer can order $q^{N L^{*}}=q^{N L}$ with no loan, $q^{L R^{*}}=\frac{T D}{w}$ with loan can be repaid and $q^{L M^{*}}=$ $\frac{T D}{w}$ with loan may be repaid. Since $q^{N L}$ is the optimal solution of $\pi_{r}^{N L}$, we obtain $\pi_{r}^{N L}\left(q^{N L}\right)>\pi_{r}^{N L}\left(\frac{T D}{w}\right)$. In addition, we obtain that $\pi_{r}^{N L}\left(\frac{T D}{w}\right)=\pi_{r}^{L R}\left(\frac{T D}{w}\right)=\pi_{r}^{L M}\left(\frac{T D}{w}\right)$. Then we get that $\pi_{r}^{N L}\left(q^{N L}\right)>\pi_{r}^{L R}\left(\frac{T D}{w}\right)=$ $\pi_{r}^{L M}\left(\frac{T D}{w}\right)$. Therefore, $\pi_{r}^{N L^{*}}>\pi_{r}^{L R^{*}}=\pi_{r}^{L M^{*}}$.

Proof of Proposition 4.5. From Propositions 4.3 and 4.4, we obtain the comparing results of the retailer's expected profits. Then we can obtain the optimal order quantity corresponding to the maximal expected profit. And then the retailer's choice of order quantity is obtained by considering voucher's price and voucher's value. The results shown in Proposition 4.5 are obtained.

Proof of Proposition 4.6. In Proposition 4.5, we obtain the retailer's choice of order quantity for a given wholesale price by considering the voucher's price and voucher's value. Then for $\beta>\hat{\beta}$, if $T<T^{L M}$, the supplier's profit function is $\pi_{s}=(w-c) q^{L R}$. Derivative of the equation with respect to $w$, we yield $\frac{\mathrm{d} \pi_{s}}{\mathrm{~d} w}=q^{L R}+(w-c) \frac{\mathrm{d} q^{L R}}{\mathrm{~d} w}$. Notice that $q^{L R}$ satisfies $p-p F\left(\frac{q^{L R}}{D}\right)-w\left(1+R_{f}\right)=0$ and by taking the derivative of it with respect to $w$, we yield $\frac{\mathrm{d} q^{L R}}{\mathrm{~d} w}=-\frac{D\left(1+R_{f}\right)}{p f\left(\frac{q^{L R}}{D}\right)}$. By substituting $\frac{\mathrm{d} q^{L R}}{\mathrm{~d} w}$ into $\frac{\mathrm{d} \pi_{s}}{\mathrm{~d} w}$, we obtain $\frac{\mathrm{d} \pi_{s}}{\mathrm{~d} w}=q^{L R}-(w-c) \frac{D\left(1+R_{f}\right)}{p f\left(\frac{q^{L R}}{D}\right)}$ and the 
second order condition of $\pi_{s}$ is $\frac{\mathrm{d}^{2} \pi_{s}}{\mathrm{~d} w^{2}}=2 \frac{\mathrm{d} q^{L R}}{\mathrm{~d} w}+(w-c) \frac{\mathrm{d}^{2} q^{L R}}{\mathrm{~d} w^{2}}=\left[2+(w-c) f^{\prime}\left(\frac{q^{L R}}{D}\right) /\left[f\left(\frac{q^{L R}}{D}\right)\right]^{2}\right] \frac{\mathrm{d} q^{L R}}{\mathrm{~d} w}<0$. Let $\frac{\mathrm{d} \pi_{s}}{\mathrm{~d} w}=0$ and submit $q^{L R}=D F^{-1}\left[1-\frac{w\left(1+R_{f}\right)}{p}\right]$ into it, we obtain that the supplier's optimal wholesale price $w^{*}=w^{L R}$ where $w^{L R}$ satisfies $p f\left(F^{-1}\left[1-\frac{w^{L R}\left(1+R_{f}\right)}{p}\right]\right) F^{-1}\left[1-\frac{w^{L R}\left(1+R_{f}\right)}{p}\right]=\left(w^{L R}-c\right)\left(1+R_{f}\right)$.

For $\beta>\hat{\beta}$, if $T^{L M} \leq T<T^{L R}$, the supplier's profit function is $\pi_{s}=(w-c) q^{L M}$. As shown in Lemma 4.2, $q^{L R}=q^{L M}$ and then the supplier's optimal wholesale price in this condition is the same as that for $\beta>\hat{\beta}$ and $T<T^{L M}$. Therefore, the supplier's optimal wholesale price is $w^{*}=w^{L M}$ which is equal to $w^{L R}$.

For $\beta>\hat{\beta}$, if $T^{L R} \leq T<T^{N L}$, the supplier's profit function is $\pi_{s}=T D-\frac{c T D}{w}$. The first order condition of $\pi_{s}$ with respect to $w$ is $\frac{\mathrm{d} \pi_{s}}{\mathrm{~d} w}=\frac{c T D}{w^{2}}>0$ which means the supplier's profit increases with her wholesale price. As shown in Lemmas 4.1 and 4.2 , when the retailer's order quantity is $\frac{T D}{w}$, the supplier's wholesale price should satisfy $w \leq T$. Then the supplier's optimal wholesale price $w^{*}=T$.

For $\beta>\hat{\beta}$, if $T \geq T^{N L}$, the supplier's profit function is $\pi_{s}=(w-c) q^{N L}$. The first order condition of $\pi_{s}$ with respect to $w$ is $\frac{\mathrm{d} \pi_{s}}{\mathrm{~d} w}=q^{N L}+(w-c) \frac{\mathrm{d} q^{N L}}{\mathrm{~d} w}$. Notice that $q^{N L}$ satisfies $p-p F\left(\frac{q^{N L}}{D}\right)-w=0$ and by taking the derivative of it with respect to $w$, we yield $\frac{\mathrm{d} q^{N L}}{\mathrm{~d} w}=-\frac{D}{p f\left(\frac{q^{N L}}{D}\right)}$. Then $\frac{\mathrm{d} \pi_{s}}{\mathrm{~d} w}=q^{N L}-(w-c) \frac{D}{p f\left(\frac{q^{N L}}{D}\right)}$. And the second order condition of $\pi_{s}$ with respect to $w$ is $\frac{\mathrm{d}^{2} \pi_{s}}{\mathrm{~d} w^{2}}=2 \frac{\mathrm{d} q^{N L}}{\mathrm{~d} w}+(w-c) \frac{\mathrm{d}^{2} q^{N L}}{\mathrm{~d} w^{2}}=\left[2+(w-c) f^{\prime}\left(\frac{q^{N L}}{D}\right) /\left[f\left(\frac{q^{N L}}{D}\right)\right]^{2}\right] \frac{\mathrm{d} q^{N L}}{\mathrm{~d} w}<$ 0 . Then the supplier's optimal wholesale price is unique in the condition. Let $\frac{\mathrm{d} \pi_{s}}{\mathrm{~d} w}=0$ and the supplier's wholesale price $w^{*}=w^{N L}$ where $w^{N L}$ satisfies $p F^{-1}\left(1-\frac{w^{N L}}{p}\right) f\left[F^{-1}\left(1-\frac{w^{N L}}{p}\right)\right]=w^{N L}-c$.

For $\beta \leq \hat{\beta}$, if $T<T^{L R}$, the supplier's profit is $\pi_{s}=(w-c) q^{L R}$ which is the same as that for $\beta>\hat{\beta}$ and $T<T^{L M}$. The supplier's optimal wholesale price in this condition is $w^{*}=w^{L R}$. For $\beta \leq \hat{\beta}$, if $T^{L R} \leq T<T^{N L}$, the supplier's profit is $\pi_{s}=T D-\frac{c T D}{w}$ which is the same as that for $\beta>\hat{\beta}$ and $T^{L R} \leq T<T^{N L}$. The supplier's optimal wholesale price in this condition is $w^{*}=T$. For $\beta \leq \hat{\beta}$, if $T \geq T^{N L}$, the supplier's profit is $\pi_{s}=(w-c) q^{N L}$ which is the same as that for $\beta>\hat{\beta}$ and $T \geq T^{N L}$. The supplier's optimal wholesale price in this condition is $w^{*}=w^{N L}$.

Above all, if $T<T^{L R}$, the supplier's optimal wholesale price is $w^{*}=w^{L}$ where $w^{L}=w^{L R}=w^{L M}$; if $T^{L R} \leq T<T^{N L}$, the supplier's optimal wholesale price is $w^{*}=T$; and if $T \geq T^{N L}$, the supplier's optimal wholesale price is $w^{*}=w^{N L}$.

Proof of Lemma 5.1. The retailer's optimal order quantity in the case without adopting trade credit financing is the same as that of the case without loan from a bank. Therefore, the retailer's optimal order quantity $q^{N R^{*}}=\frac{T D}{w_{C}}$ if $T<w_{C} F^{-1}\left(1-\frac{w_{C}}{p}\right)$ and $q^{N R^{*}}=q^{N R}$ if $T \geq w_{C} F^{-1}\left(1-\frac{w_{C}}{p}\right)$, where $q^{N R}=D F^{-1}\left(1-\frac{w_{C}}{p}\right)$.

By adopting trade credit financing, in the condition that the financing can be repaid, the objective function of (5.1) is reduced to

$$
\pi_{r}^{C R}=p q-\beta T D-p D \int_{u}^{\frac{q}{D}} F(\alpha) \mathrm{d} \alpha-w_{C} q+T D .
$$

The first order condition of $\pi_{r}^{C R}$ with respect to $q$ is $\frac{\mathrm{d} \pi_{r}^{C R}}{\mathrm{~d} q}=p-p F\left(\frac{q}{D}\right)-w_{C}$ and the second order condition of $\pi_{r}^{C R}$ with respect to $q$ is $\frac{\mathrm{d}^{2} \pi_{r}^{C R}}{\mathrm{~d} q^{2}}=-\frac{p}{D} f\left(\frac{q}{D}\right)<0$. Then the optimal $q^{C R}$ satisfies $p-p F\left(\frac{q^{C R}}{D}\right)-w_{C}=0$ and $q^{C R}=D F^{-1}\left(1-\frac{w_{C}}{p}\right)$ is the unique optimal solution.

Considering the first constraint in (5.1), we get that if $T \geq w_{C} F^{-1}\left(1-\frac{w_{C}}{p}\right)$, the retailer's optimal order quantity $q^{C R^{*}}=\frac{T D}{w_{C}}$. If the first constraint is satisfied, that is $T<w_{C} F^{-1}\left(1-\frac{w_{C}}{p}\right)$, the retailer borrows from a bank and $q^{C R^{*}}=q^{C R}$ if the second constrained is also satisfied, that is $T \leq \frac{p-w_{C} F^{-1}\left(1-\frac{w_{C}}{p}\right)}{\beta-1}$. If $T<w_{C} F^{-1}\left(1-\frac{w_{C}}{p}\right)$ and $T>\frac{p-w_{C} F^{-1}\left(1-\frac{w_{C}}{p}\right)}{\beta-1}$, the retailer's optimal order quantity $q^{C R^{*}}=\frac{(p-\beta T) D+T D}{w_{C}}$. 
In the condition that the trade credit financing may be repaid, the objective function of (5.2) is reduced to

$$
\pi_{r}^{C M}=\left(p q-\beta T D-w_{C} q+T D\right)-\int_{\frac{\beta T D-T D+w_{C} q}{p D}}^{\frac{q}{D}} p D F(\alpha) \mathrm{d} \alpha .
$$

The first order condition of $\pi_{r}^{C M}$ with respect to $q$ is $\frac{\mathrm{d} \pi_{r}^{C M}}{\mathrm{~d} q}=p-w_{C}-p F\left(\frac{q}{D}\right)+w_{C} F\left(\frac{\beta T D-T D+w_{C} q}{p D}\right)$ and the second order condition of $\pi_{r}^{C M}$ with respect to $q$ is $\frac{\mathrm{d}^{2} \pi_{r}^{C M}}{\mathrm{~d} q^{2}}=-p f\left(\frac{q}{D}\right) \frac{1}{D}+w_{C} f\left(\frac{\beta T D-T D+w_{C} q}{p D}\right) \frac{w_{C}}{p D}<0$. Then the optimal $q^{C M}$ satisfies $p \bar{F}\left(\frac{q^{C M}}{D}\right)=w_{C} \bar{F}\left(\frac{\beta T D-T D+w_{C} q^{C M}}{p D}\right)$.

By substituting $q^{C M}$ into the constraints in (5.2), we get that $T<\frac{w_{C} q^{C M}}{D}, T>\frac{p D-w_{C} q^{C M}}{D(\beta-1)}$ and $q^{C M} \geq$ $D$, where $q^{C M} \geq D$ is always satisfied because $p F\left(\frac{D}{D}\right)=0$ while $p F\left(\frac{q^{c M}}{D}\right)$ in $p-w_{C}=p F\left(\frac{q^{C M}}{D}\right)-$ $w_{C} F\left(\frac{\beta T D-T D+w_{C} q^{C M}}{p D}\right)$ should be positive to ensure the equation is satisfied. Then if $T \geq \frac{w_{C} q^{C M}}{D}$, the retailer orders with all revenue from voucher sale, that is $q^{C M^{*}}=\frac{T D}{w_{C}}$; if $T<\frac{w_{C} q^{C M}}{D}$ and $T>\frac{p D-w_{C} q^{C M}}{D(\beta-1)}$, the retailer gets the optimal order quantity $q^{C M^{*}}=q^{C M}$; and if $T<\frac{w_{C} q^{C M}}{D}$ and $T \leq \frac{p D-w_{C} q^{C M}}{D(\beta-1)}$, the retailer orders with all revenue from voucher sale and demand of consumers with voucher, that is $q^{C M^{*}}=\frac{(p-\beta T) D+T D}{w_{C}}$.

Proof of Proposition 5.2. As shown in Lemma 5.1, the boundaries of the firms' decisions are $\tilde{w}_{C}, \frac{p-\tilde{w}_{C}}{\beta-1}, \frac{w_{C} q^{C M}}{D}$ and $\frac{p D-w_{C} q^{C M}}{D(\beta-1)}$. Notice that $\tilde{w}_{C}=\frac{w_{C} q^{N R}}{D}, F\left(\frac{q^{N R}}{D}\right)=1-\frac{w_{C}}{p}$ and $F\left(\frac{q^{C M}}{D}\right)=1-\frac{w_{C}}{p} \bar{F}\left(\frac{\beta T D-T D+w_{C} q^{C M}}{p D}\right)$. We get $q^{N R}<q^{C M}$ and then $\tilde{w}_{C}<\frac{w_{C} q^{C M}}{D}$ and $\frac{p-\tilde{w}_{C}}{\beta-1}>\frac{p D-w_{C} q^{C M}}{D(\beta-1)}$ always exist. By simple calculation, we get that if $\beta<\frac{p D}{w_{C} q^{C M}}, \tilde{w}_{C}<\frac{w_{C} q^{C M}}{D}<\frac{p D-w_{C} q^{C M}}{D(\beta-1)}<\frac{p-\tilde{w}_{C}}{\beta-1}$; if $\frac{p D}{w_{C} q^{C M}} \leq \beta<\frac{p D-w_{C} q^{N R}+w_{C} q^{C M}}{w_{C} q^{C M}}$, $\tilde{w}_{C}<\frac{p D-w_{C} q^{C M}}{D(\beta-1)}<\frac{w_{C} q^{C M}}{D}<\frac{p-\tilde{w}_{C}}{\beta-1}$; if $\frac{p D-w_{C} q^{N R}+w_{C} q^{C M}}{w_{C} q^{C M}} \leq \beta<\frac{p D}{w_{C} q^{N R}}, \tilde{w}_{C}<\frac{p D-w_{C} q^{C M}}{D(\beta-1)}<\frac{p-\tilde{w}_{C}}{\beta-1}<\frac{w_{C} q^{C M}}{D}$; and if $\beta \geq \frac{p D}{w_{C} q^{N R}}, \frac{p D-w_{C} q^{C M}}{D(\beta-1)}<\frac{p-\tilde{w}_{C}}{\beta-1}<\tilde{w}_{C}<\frac{w_{C} q^{C M}}{D}$. From the objective functions of (4.1), (5.1) and (5.2), we obtain that $\pi_{r}^{N R}=p q-\beta T D-w_{C} q+T D-p D \int_{u}^{\frac{q}{D}} F(\alpha) \mathrm{d} \alpha, \pi_{r}^{C R}=\left(p q-\beta T D-w_{C} q+T D\right)-p D \int_{u}^{\frac{q}{D}} F(\alpha) \mathrm{d} \alpha$ and $\pi_{r}^{C M}=\left(p q-\beta T D-w_{C} q+T D\right)-p D \int_{\frac{\beta T D-T D+w_{C} q}{p D}}^{\frac{q}{D}} F(\alpha) \mathrm{d} \alpha$. And then we obtain that $\pi_{r}^{N R}(q)=$ $\pi_{r}^{C R}(q), \pi_{r}^{C R}\left(\frac{T D}{w_{C}}\right)=\pi_{r}^{C M}\left(\frac{T D}{w_{C}}\right), \pi_{r}^{C R}\left(\frac{(p-\beta T) D+T D}{w_{C}}\right)=\pi_{r}^{C M}\left(\frac{(p-\beta T) D+T D}{w_{C}}\right)$ and $\pi_{r}^{C M}(q)-\pi_{r}^{C R}(q)=$ $p D\left[\int_{u}^{\frac{q}{D}} F(\alpha) \mathrm{d} \alpha-\int_{\frac{\beta T D-T D+w_{C} q}{p D}}^{\frac{q}{D}} F(\alpha) \mathrm{d} \alpha\right]>0$.

Then for $\beta<\frac{p D}{w_{C} q^{C M}}$, if $T<\tilde{w}_{C}$, the retailer's order quantities can be $q^{N R^{*}}=\frac{T D}{w_{C}}, q^{C R^{*}}=q^{C R}$ and $q^{C M^{*}}=$ $\frac{(p-\beta T) D+T D}{w_{C}}$. Because $\pi_{r}^{N R}(q)=\pi_{r}^{C R}(q)$, then $\pi_{r}^{N R}\left(\frac{T D}{w_{C}}\right)=\pi_{r}^{C R}\left(\frac{T D}{w_{C}}\right)$ is satisfied. Notice that $q^{C R}$ is the optimal solution of $\pi_{r}^{C R}$, then we obtain that $\pi_{r}^{C R}\left(q^{C R}\right)>\pi_{r}^{C R}\left(\frac{T D}{w_{C}}\right)$ and $\pi_{r}^{C R}\left(q^{C R}\right)>\pi_{r}^{C R}\left(\frac{(p-\beta T) D+T D}{w_{C}}\right)$. Then $q^{C R}$ is the retailer's optimal choice of order quantity. If $\tilde{w}_{C} \leq T<\frac{w_{C q}^{C M}}{D}$, the retailer's order quantities can be $q^{N R^{*}}=q^{N R}, q^{C R^{*}}=\frac{T D}{w_{C}}$ and $q^{C M^{*}}=\frac{(p-\beta T) D+T D}{w_{C}}$. Notice that $q^{N R}$ is the optimal solution of $\pi_{r}^{N R}$, we obtain that $\pi_{r}^{N R}\left(q^{N R}\right)>\pi_{r}^{N R}\left(\frac{T D}{w_{C}}\right)$ and $\pi_{r}^{N R}\left(q^{N R}\right)>\pi_{r}^{N R}\left(\frac{(p-\beta T) D+T D}{w_{C}}\right)$. Because $\pi_{r}^{N R}(q)=\pi_{r}^{C R}(q)$ and $\pi_{r}^{C R}\left(\frac{(p-\beta T) D+T D}{w_{C}}\right)=\pi_{r}^{C M}\left(\frac{(p-\beta T) D+T D}{w_{C}}\right), q^{N R}$ is the retailer's optimal choice of order quantity. If $T \geq$ $\frac{w_{C} q^{C M}}{D}$, the retailer's order quantities can be $q^{N R^{*}}=q^{N R}, q^{C R^{*}}=\frac{T D}{w_{C}}$ and $q^{C M^{*}}=\frac{T D}{w_{C}}$. We have already obtained that $\pi_{r}^{N R}\left(q^{N R}\right)>\pi_{r}^{C R}\left(\frac{T D}{w_{C}}\right)$ and $\pi_{r}^{C R}\left(\frac{T D}{w_{C}}\right)=\pi_{r}^{C M}\left(\frac{T D}{w_{C}}\right)$. Then $q^{N R}$ is the optimal choice of order quantity. Thus, $q^{C R}$ is the retailer's optimal choice of order quantity if $T<\tilde{w}_{C}$ and $q^{N R}$ is the retailer's optimal choice of order quantity if $T \geq \widetilde{w}_{C}$. 
For $\frac{p D}{w_{C} q^{C M}} \leq \beta<\frac{p D}{w_{C} q^{N R}}$, if $T<\tilde{w}_{C}$, the retailer's order quantities can be $q^{N R^{*}}=\frac{T D}{w_{C}}, q^{C R^{*}}=q^{C R}$ and $q^{C M^{*}}=\frac{(p-\beta T) D+T D}{w_{C}}$. Similar to that in the condition of $\beta<\frac{p D}{w_{C} q^{C M}}$ and $T<\widetilde{w}_{C}, q^{C R}$ is the retailer's optimal choice of order quantity. If $\tilde{w}_{C} \leq T<\frac{p D-w_{C} q^{C M}}{D(\beta-1)}$, the retailer's order quantities can be $q^{N R^{*}}=q^{N R}, q^{C R^{*}}=\frac{T D}{w_{C}}$ and $q^{C M^{*}}=\frac{(p-\beta T) D+T D}{w_{C}}$ which is the same as that in the condition of $\beta<\frac{p D}{w_{C} q^{C M}}$ and $\tilde{w}_{C} \leq T<\frac{w_{C} q^{C M}}{D}$. Then $q^{N R}$ is the retailer's optimal choice of order quantity. If $\frac{p D-w_{C} q^{C M}}{D(\beta-1)} \leq T<\frac{w_{C} q^{C M}}{D}$, the retailer's order quantities can be $q^{N R^{*}}=q^{N R}, q^{C R^{*}}=\frac{T D}{w_{C}}$ and $q^{C M^{*}}=q^{c M}$. Because $\pi_{r}^{C M}(q)-\pi_{r}^{C R}(q)>0$, we obtain $\pi_{r}^{C M}\left(q^{N R}\right)-\pi_{r}^{C R}\left(q^{N R}\right)>0$. As $q^{C M}$ is the optimal solution of $\pi_{r}^{C M}, \pi_{r}^{C M}\left(q^{C M}\right)>\pi_{r}^{C M}\left(q^{N R}\right)$ is satisfied. Then $\pi_{r}^{C M}\left(q^{C M}\right)>\pi_{r}^{C R}\left(q^{N R}\right)$. And because $\pi_{r}^{N R}(q)=\pi_{r}^{C R}(q), \pi_{r}^{N R}\left(q^{N R}\right)=\pi_{r}^{C R}\left(q^{N R}\right)$. Therefore, $\pi_{r}^{C M}\left(q^{C M}\right)>\pi_{r}^{N R}\left(q^{N R}\right)$. Besides, we obtain that $\pi_{r}^{N R}\left(q^{N R}\right)>\pi_{r}^{C R}\left(\frac{T D}{w_{C}}\right)$ and then $\pi_{r}^{C M}\left(q^{C M}\right)>$ $\pi_{r}^{N R}\left(q^{N R}\right)>\pi_{r}^{C R}\left(\frac{T D}{w_{C}}\right)$. Thus, $q^{C M}$ is the retailer's optimal choice of order quantity. If $T \geq \frac{w_{C} q^{C M}}{D}$, the retailer's order quantities can be $q^{N R^{*}}=q^{N R}, q^{C R^{*}}=\frac{T D}{w_{C}}$ and $q^{C M^{*}}=\frac{T D}{w_{C}}$ which is the same as that in the condition of $\beta<\frac{p D}{w_{C} q^{C M}}$ and $T \geq \frac{w_{C} q^{C M}}{D}$. Then $q^{N R}$ is the retailer's optimal choice of order quantity. Thus, $q^{C R}$ is the retailer's optimal choice of order quantity if $T<\tilde{w}_{C}, q^{N R}$ is the retailer's optimal choice of order quantity if $\tilde{w}_{C} \leq T<\frac{w_{C} q^{C M}}{D}, q^{C M}$ is the retailer's optimal choice of order quantity if $\frac{p D-w_{C} q^{C M}}{D(\beta-1)} \leq T<\frac{w_{C} q^{C M}}{D}$ and $q^{N R}$ is the retailer's optimal choice of order quantity if $T \geq \frac{w_{C} q^{C M}}{D}$.

For $\beta \geq \frac{p D}{w_{C} q^{N R}}$, if $T<\frac{p D-w_{C} q^{C M}}{D(\beta-1)}$, the retailer's order quantities can be $q^{N R^{*}}=\frac{T D}{w_{C}}, q^{C R^{*}}=q^{C R}$ and $q^{C M^{*}}=\frac{(p-\beta T) D+T D}{w_{C}}$. Similar to that in the condition of $\beta<\frac{p D}{w_{C} q^{C M}}$ and $T<\widetilde{w}_{C}, q^{C R}$ is the retailer's optimal choice of order quantity. If $\frac{p D-w_{C} q^{C M}}{D(\beta-1)} \leq T<\frac{p-\tilde{w}_{C}}{\beta-1}$, the retailer's order quantities can be $q^{N R^{*}}=\frac{T D}{w_{C}}$, $q^{C R^{*}}=q^{C R}$ and $q^{C M^{*}}=q^{C M}$. Because $\pi_{r}^{C M}(q)-\pi_{r}^{C R}(q)>0$, we obtain $\pi_{r}^{C M}\left(q^{C R}\right)-\pi_{r}^{C R}\left(q^{C R}\right)>0$. As $q^{C M}$ is the optimal solution of $\pi_{r}^{C M}, \pi_{r}^{C M}\left(q^{C M}\right)>\pi_{r}^{C M}\left(q^{C R}\right)$ is satisfied. Then $\pi_{r}^{C M}\left(q^{C M}\right)>\pi_{r}^{C R}\left(q^{C R}\right)$. Notice that $q^{C R}$ is the optimal solution of $\pi_{r}^{C R}$, we obtain that $\pi_{r}^{C R}\left(q^{C R}\right)>\pi_{r}^{C R}\left(\frac{T D}{w_{C}}\right)$. And because $\pi_{r}^{N R}(q)=\pi_{r}^{C R}(q), \pi_{r}^{N R}\left(\frac{T D}{w_{C}}\right)=\pi_{r}^{C R}\left(\frac{T D}{w_{C}}\right)$. We obtain that $\pi_{r}^{C R}\left(q^{C R}\right)>\pi_{r}^{N R}\left(\frac{T D}{w_{C}}\right)$. Therefore, we obtain $\pi_{r}^{C M}\left(q^{C M}\right)>\pi_{r}^{C R}\left(q^{C R}\right)>\pi_{r}^{N R}\left(\frac{T D}{w_{C}}\right)$. Thus, $q^{C M}$ is the retailer's optimal choice of order quantity. If $\frac{p-\tilde{w}_{C}}{\beta-1} \leq T<\tilde{w}_{C}$, the retailer's order quantities can be $q^{N R^{*}}=\frac{T D}{w_{C}}, q^{C R^{*}}=\frac{(p-\beta T) D+T D}{w_{C}}$ and $q^{C M^{*}}=q^{C M}$. We obtain that $\pi_{r}^{C M}\left(q^{C M}\right)>\pi_{r}^{C M}\left(\frac{T D}{w_{C}}\right)$ and $\pi_{r}^{C M}\left(q^{C M}\right)>\pi_{r}^{C M}\left(\frac{(p-\beta T) D+T D}{w_{C}}\right)$ for $q^{C M}$ is the optimal solution of $\pi_{r}^{C M}$. Because $\pi_{r}^{N R}(q)=\pi_{r}^{C R}(q), \pi_{r}^{C R}\left(\frac{T D}{w_{C}}\right)=\pi_{r}^{C M}\left(\frac{T D}{w_{C}}\right)$ and $\pi_{r}^{C R}\left(\frac{(p-\beta T) D+T D}{w_{C}}\right)=\pi_{r}^{C M}\left(\frac{(p-\beta T) D+T D}{w_{C}}\right)$ are satisfied, we obtain $\pi_{r}^{C M}\left(q^{C M}\right)>\pi_{r}^{N R}\left(\frac{T D}{w_{C}}\right)$ and $\pi_{r}^{C M}\left(q^{C M}\right)>\pi_{r}^{C R}\left(\frac{(p-\beta T) D+T D}{w_{C}}\right)$. Then $q^{C M}$ is the retailer's optimal choice of order quantity. If $\tilde{w}_{C} \leq T<\frac{w_{C} q^{C M}}{D}$, the retailer's order quantities can be $q^{N R^{*}}=q^{N R}, q^{C R^{*}}=\frac{T D}{w_{C}}$ and $q^{C M^{*}}=q^{C M}$ which is similar to that in the condition of $\frac{p D}{w_{C} q^{C M}} \leq \beta<\frac{p D}{w_{C} q^{N R}}$ and $\frac{p D-w_{C} q^{C M}}{D(\beta-1)} \leq T<\frac{w_{C} q^{C M}}{D}$. Then $q^{C M}$ is the retailer's optimal choice of order quantity. If $T \geq \frac{w_{C} q^{C M}}{D}$, the retailer's order quantities can be $q^{N R^{*}}=q^{N R}, q^{C R^{*}}=\frac{T D}{w_{C}}$ and $q^{C M^{*}}=\frac{T D}{w_{C}}$ which is the same as that in the condition of $\beta<\frac{p D}{w_{C} q^{C M}}$ and $T \geq \frac{w_{C} q^{C M}}{D}$. Then $q^{N R}$ is the retailer's optimal choice of order quantity. Thus, $q^{C R}$ is the retailer's optimal choice of order quantity if $T<\frac{p D-w_{C} q^{C M}}{D(\beta-1)}, q^{C M}$ is the retailer's optimal choice of order quantity if $\frac{p D-w_{C} q^{C M}}{D(\beta-1)} \leq T<\frac{w_{C} q^{C M}}{D}$, and $q^{N R}$ is the retailer's optimal choice of order quantity if $T \geq \frac{w_{C} q^{C M}}{D}$.

Proof of Proposition 5.3. From Proposition 5.2, we obtain that the retailer may order $q^{N R}, q^{C R}$ or $q^{C M}$ by considering the voucher's price and voucher's value. By anticipating that the retailer orders $q^{N R}$, the sup- 
plier's profit function is $\pi_{s}^{C}=w_{C} q^{N R}-c q^{N R}$. The first order condition of $\pi_{s}^{C}$ with respect to $w_{C}$ is $\frac{\mathrm{d} \pi_{s}^{C}}{\mathrm{~d} w_{C}}=q^{N R}+w_{C} \frac{\mathrm{d} q^{N R}}{\mathrm{~d} w_{C}}-c \frac{\mathrm{d} q^{N R}}{\mathrm{~d} w_{C}}$ where $\frac{\mathrm{d} q^{N R}}{\mathrm{~d} w_{C}}=-\frac{D}{p f\left(\frac{q^{N R}}{D}\right)}$ by taking the derivative of $p-p F\left(\frac{q^{N R}}{D}\right)-$ $w_{C}=0$ with respect to $w_{C}$. The second order condition of $\pi_{s}^{C}$ with respect to $w_{C}$ is $\frac{\mathrm{d}^{2} \pi_{s}^{C}}{\mathrm{~d} w_{C}^{2}}=2 \frac{\mathrm{d} q^{N R}}{\mathrm{~d} w_{C}}+$ $\left(w_{C}-c\right) \frac{\mathrm{d}^{2} q^{N R}}{\mathrm{~d} w_{C}^{2}}=\left[2+\left(w_{C}-c\right) f^{\prime}\left(\frac{q^{N R}}{D}\right) /\left[f\left(\frac{q^{N R}}{D}\right)\right]^{2}\right] \frac{\mathrm{d} q^{N R}}{\mathrm{~d} w_{C}}<0$. Then the supplier's optimal wholesale price is unique. Let $\frac{\mathrm{d} \pi_{s}^{C}}{\mathrm{~d} w_{C}}=0$ and the supplier's wholesale price $w_{C}^{*}=w_{C}^{N R}$ where $w_{C}^{N R}$ satisfies $p F^{-1}\left(1-\frac{w_{C}^{N R}}{p}\right) f\left[F^{-1}\left(1-\frac{w_{C}^{N R}}{p}\right)\right]=w_{C}^{N R}-c$. Because $q^{C R}=q^{N R}$, the supplier's optimal wholesale price $w_{C}^{*}=w_{C}^{C R}$ where $w_{C}^{C R}=w_{C}^{N R}$ by anticipating the retailer's order quantity is $q^{C R}$. Define $w_{C}^{C N}=w_{C}^{N R}=w_{C}^{C R}$ and $q^{C N}=q^{N R}=q^{C R}$, and then $w_{C}^{C N}$ satisfies $p F^{-1}\left(1-\frac{w_{C}^{C N}}{p}\right) f\left[F^{-1}\left(1-\frac{w_{C}^{C N}}{p}\right)\right]=w_{C}^{C N}-c$.

By anticipating the retailer's order quantity is $q^{C M}$, the supplier's profit function is reduced to $\pi_{s}^{C}=w_{C} q-$ $c q-p D \int_{u}^{\frac{\beta T D-T D+w_{C} q}{p D}} F(\alpha) \mathrm{d} \alpha$. The first condition of $\pi_{s}^{C}$ with respect to $w_{C}$ is $\frac{\mathrm{d} \pi_{s}^{c}}{\mathrm{~d} w_{C}}=q^{C M}+w_{C} \frac{\mathrm{d} q^{C M}}{\mathrm{~d} w_{C}}-c \frac{\mathrm{d} q^{C M}}{\mathrm{~d} w_{C}}-$ $F\left(\frac{\beta T D-T D+w_{C} q^{c M}}{p D}\right)\left(q^{C M}+w_{C} \frac{\mathrm{d} q^{C M}}{\mathrm{~d} w_{C}}\right)$. We obtain that $\frac{\mathrm{d} q^{C M}}{\mathrm{~d} w_{C}}=w_{C} \bar{F}\left(\frac{\beta T D-T D+w_{C} q^{C M}}{p D}\right)$ with respect to $w_{C}$. And then we obtain that $\frac{\mathrm{d} \pi_{s}^{C M}}{\mathrm{~d} w_{C}}=\left[p^{2} D \bar{F}\left(\frac{q^{C M}}{D}\right) \bar{F}\left(\frac{\beta T D-T D+w_{C} q^{C M}}{p D}\right)-p^{2} q^{C M} f\left(\frac{q^{C M}}{D}\right) \bar{F}\left(\frac{\beta T D-T D+w_{C} q^{C M}}{p D}\right)-\right.$ $\left.c p D \bar{F}\left(\frac{\beta T D-T D+w_{C} q^{C M}}{p D}\right)+c w_{C} q^{C M} f\left(\frac{\beta T D-T D+w_{C} q^{C M}}{p D}\right)\right] /\left[w_{C}^{2} f\left(\frac{\beta T D-T D+w_{C} q^{C M}}{p D}\right)-p^{2} f\left(\frac{q^{C M}}{D}\right)\right]$. The supplier's optimal wholesale price satisfies $\frac{\mathrm{d} \pi_{s}^{C}}{\mathrm{~d} w_{C}}=0$, and then $w_{C}^{*}=w_{C}^{C M}$ where $c w_{C}^{C M} q^{C M} \frac{f\left(\frac{\beta T D-T D+w_{C}^{C M} q_{q}^{C M}}{p D}\right)}{\bar{F}\left(\frac{\beta T D-T D+w_{C}^{C M} q_{q} C M}{p D}\right)}=$ $p^{2} q^{C M} f\left(\frac{q^{C M}}{D}\right)-p^{2} D \bar{F}\left(\frac{q^{C M}}{D}\right)+c p D$.

Above all, for $\beta<\frac{p D}{w^{C N} q^{C N}}, w_{C}^{*}=w_{C}^{C N}$; for $\beta \geq \frac{p D}{w^{C N} q^{C N}}, \quad w_{C}^{*}=w_{C}^{C N}$ if $T<\frac{p D-w_{C}^{C M} q^{C M}}{D(\beta-1)}, w_{C}{ }^{*}=w_{C}^{C M}$ if $\frac{p D-w_{C}^{C M} q^{C M}}{D(\beta-1)} \leq T<\frac{w_{C}^{C M} q^{C M}}{D}, w_{C}^{*}=w_{C}^{C N}$ if $T \geq \frac{w_{C}^{C M} q^{C M}}{D}$.

Acknowledgements. The authors would like to thank the anonymous reviewers and the editor for their valuable comments and suggestions which helped to improve the present paper. This work was supported by (i) National Natural Science Foundation of China (72002104); (ii) Jiangsu Social Science Foundation (20GLC007) and (iii) the Fundamental Research Funds for the Central Universities (2232018H-09).

\section{REFERENCES}

[1] J.A. Buzacott and R.Q Zhang, Inventory management with asset-based financing. Manage. Sci. 50 (2004) 1274-1292.

[2] G.P. Cachon and P. Feldman, Is advance selling desirable with competition? Marketing Sci. 36 (2017) $214-231$.

[3] G. Cai, X. Chen and Z. Xiao, The roles of bank and trade credits: theoretical analysis and empirical evidence. Prod. Oper. Manage. 23 (2014) 583-598.

[4] E. Cao, L. Du and J. Ruan, Financing preferences and performance for an emission-dependent supply chain: supplier vs. bank. Int. J. Prod. Econ. 208 (2019) 383-399.

[5] X. Chen, A model of trade credit in a capital-constrained distribution channel. Int. J. Prod. Econ. 159 (2015) $347-357$.

[6] X. Chen, G. Cai and J.-S. Song, The cash flow advantages of 3pls as supply chain orchestrators. Manuf. Serv. Oper. Manage. 21 (2019) 435-451.

[7] Y. Cheng, H. Li and A. Thorstenson, Advance selling with double marketing efforts in a newsvendor framework. Comput. Ind. Eng. 118 (2018) 352-365.

[8] P. Chintapalli, S.M. Disney and C.S. Tang, Coordinating supply chains via advance-order discounts, minimum order quantities, and delegations. Prod. Oper. Manage. 26 (2017) 2175-2186.

[9] S.-H. Cho and C.S. Tang, Advance selling in a supply chain under uncertain supply and demand. Manuf. Serv. Oper. Manage. 15 (2013) 305-319.

[10] J. Chod, Inventory, risk shifting, and trade credit. Manage. Sci. 63 (2017) 3207-3225.

[11] T.-M. Choi and S. Guo, Is a 'free lunch'a good lunch? The performance of zero wholesale price-based supply-chain contracts. Eur. J. Oper. Res. 285 (2020) 237-246. 
[12] A.Y.L. Chong, E. Ch'ng, M.J. Liu and B. Li, Predicting consumer product demands via big data: the roles of online promotional marketing and online reviews. Int. J. Prod. Res. 55 (2017) 5142-5156.

[13] S. Deng, C. Gu, G. Cai and Y. Li, Financing multiple heterogeneous suppliers in assembly systems: buyer finance vs. bank finance. Manuf. Serv. Oper. Manage. 20 (2018) 53-69.

[14] S.K. Devalkar and H. Krishnan, The impact of working capital financing costs on the efficiency of trade credit. Prod. Oper. Manage. 28 (2019) 878-889.

[15] W. Ding and G. Wan, Financing and coordinating the supply chain with a capital-constrained supplier under yield uncertainty. Int. J. Prod. Econ. 230 (2020) 107813.

[16] G.-X. Gao, Z.-P. Fan, X. Fang and Y.F. Lim, Optimal stackelberg strategies for financing a supply chain through online peer-to-peer lending. Eur. J. Oper. Res. 267 (2018) 585-597.

[17] J.F. Houston, C. Lin and Z. Zhu, The financial implications of supply chain changes. Manage. Sci. 62 (2016) $2520-2542$.

[18] Y. Jiang, J. Shang, Y. Liu and J. May, Redesigning promotion strategy for e-commerce competitiveness through pricing and recommendation. Int. J. Prod. Econ. 167 (2015) 257-270.

[19] Y. Jiang, Y. Liu, J. Shang, P. Yildirim and Q. Zhang, Optimizing online recurring promotions for dual-channel retailers: Segmented markets with multiple objectives. Eur. J. Oper. Res. 267 (2018) 612-627.

[20] W. Jin, J. Luo and Q. Zhang, Optimal ordering and financing decisions under advance selling and delayed payment for a capital-constrained supply chain. J. Oper. Res. Soc. 69 (2018) 1978-1993.

[21] B. Jing, X. Chen and G. Cai, Equilibrium financing in a distribution channel with capital constraint. Prod. Oper. Manage. 21 (2012) 1090-1101.

[22] M. Kenney and J. Zysman, The rise of the platform economy. Issues Sci. Technol. 32 (2016) 61.

[23] M. Khouja and J. Zhou, Channel and pricing decisions in a supply chain with advance selling of gift cards. Eur. J. Oper. Res. 244 (2015) 471-489.

[24] Y. Kim and R. Krishnan, The dynamics of online consumers' response to price promotion. Inf. Syst. Res. 30 (2019) 175-190.

[25] P. Kouvelis and W. Zhao, Financing the newsvendor: supplier vs. bank, and the structure of optimal trade credit contracts. Oper. Res. 60 (2012) 566-580.

[26] X. Lu and Z. Wu, How taxes impact bank and trade financing for multinational firms. Eur. J. Oper. Res. 286 (2020) $218-232$.

[27] Q. Lu, J. Gu and J. Huang, Supply chain finance with partial credit guarantee provided by a third-party or a supplier. Comput. Ind. Eng. 135 (2019) 440-455.

[28] H.I. Mesak, H. Zhang and J.M. Pullis, On optimal service capacity allocation policy in an advance selling environment in continuous time. Eur. J. Oper. Res. 203 (2010) 505-512.

[29] J. Nasiry and I. Popescu, Advance selling when consumers regret. Manage. Sci. 58 (2012) 1160-1177.

[30] J. Ni, L.K. Chu and Q. Li, Capacity decisions with debt financing: the effects of agency problem. Eur. J. Oper. Res. 261 (2017) 1158-1169.

[31] T. Noparumpa, B. Kazaz and S. Webster, Wine futures and advance selling under quality uncertainty. Manuf. Serv. Oper. Manage. 17 (2015) 411-426.

[32] Z. Pang, W. Xiao and X. Zhao, Preorder price guarantee in e-commerce. Manuf. Serv. Oper. Manage. 23 (2021) $123-138$.

[33] N.S. Sahni, D. Zou and P.K. Chintagunta, Do targeted discount offers serve as advertising? evidence from 70 field experiments. Manage. Sci. 63 (2017) 2688-2705.

[34] T.I. Tunca and W. Zhu, Buyer intermediation in supplier finance. Manage. Sci. 64 (2018) 5631-5650.

[35] C. Wang, X. Fan and Z. Yin, Financing online retailers: bank vs. electronic business platform, equilibrium, and coordinating strategy. Eur. J. Oper. Res. 276 (2019) 343-356.

[36] M.M. Wei and F. Zhang, Advance selling to strategic consumers: preorder contingent production strategy with advance selling target. Prod. Oper. Manage. 27 (2018) 1221-1235.

[37] Q. Wu, K. Muthuraman and S. Seshadri, Effect of financing costs and constraints on real investments: the case of inventories. Prod. Oper. Manage. 28 (2019) 2573-2593.

[38] D. Wu, B. Zhang and O. Baron, A trade credit model with asymmetric competing retailers. Prod. Oper. Manage. 28 (2019) 206-231.

[39] M. Wu, S.X. Zhu and R.H. Teunter, Advance selling and advertising: A newsvendor framework. Decis. Sci. 52 (2021) $182-215$.

[40] L. Xiao, M. Xu, Z. Chen and X. Guan, Optimal pricing for advance selling with uncertain product quality and consumer fitness. J. Oper. Res. Soc. 70 (2019) 1457-1474.

[41] N. Yan, Y. Liu, X. Xu and X. He, Strategic dual-channel pricing games with e-retailer finance. Eur. J. Oper. Res. 283 (2020) 138-151.

[42] S.A. Yang and J.R. Birge, Trade credit, risk sharing, and inventory financing portfolios. Manage. Sci. 64 (2018) 3667-3689.

[43] L. Yang, R. Gao and S. Tong. Research on online shopping problems behind the "double eleven" shopping festival. In: The Strategies of China's Firms. Elsevier (2015) 137-147.

[44] M. Yu, R. Kapuscinski and H.-S. Ahn, Advance selling: effects of interdependent consumer valuations and seller's capacity. Manage. Sci. 61 (2015) 2100-2117.

[45] J. Zhan, A financing model with rebate contract in a capital-constrained supply chain. RAIRO:OR 55 (2021) S811-S836.

[46] J. Zhang, S. Zhao, T.C.E. Cheng and G. Hua, Optimisation of online retailer pricing and carrier capacity expansion during low-price promotions with coordination of a decentralised supply chain. Int. J. Prod. Res. 57 (2019) 2809-2827. 